\title{
Sensitivity of simulated climate over the MENA region related to different land surface schemes in the WRF model
}

\author{
Katiana Constantinidou ${ }^{1}$ - Panos Hadjinicolaou ${ }^{1}$ - George Zittis ${ }^{1}$ • Jos Lelieveld ${ }^{1,2}$
}

Received: 13 November 2019 / Accepted: 4 May 2020 / Published online: 10 June 2020

(C) The Author(s) 2020

\begin{abstract}
The effects of different land surface scheme (LSS) implementations on the simulated climate of the Middle East and North Africa (MENA) have been investigated with the Weather Research and Forecasting (WRF) regional model. Six simulations were carried out using four different LSSs (Noah, NoahMP, CLM, RUC) for the period 2000-2010, driven by ERA-Interim meteorological reanalyses at a horizontal resolution of $50 \mathrm{~km}$. Deviations of key surface climate variables, radiation, and turbulent fluxes from the different LSS runs are presented relative to the default Noah scheme. The simulated annual mean climate variables in the MENA (indicating uncertainty) range from 0.7 to $2.4{ }^{\circ} \mathrm{C}$ for air temperature, 2.0 to $3.4{ }^{\circ} \mathrm{C}$ for land temperature, and 5 to $25 \mathrm{~mm} /$ month (54-65\%) for precipitation. The Noah scheme deviates less than $-1 \mathrm{~W} / \mathrm{m}^{2}$ from the domain-wide surface energy balance and the NoahMP less than $-2 \mathrm{~W} / \mathrm{m}^{2}$, while for CLM and RUC the deviation is 3$4 \mathrm{~W} / \mathrm{m}^{2}$. Considering the differences among the surface energy balance from the various LSSs compared to the reference Noah, a surface climate response is calculated, and average LSS-induced climate sensitivity is derived for the air (and land) temperature of $0.1^{\circ} \mathrm{C}$ per W/m $/ \mathrm{m}^{2}$ and $-6 \mathrm{~mm}$ per W/m $/ \mathrm{m}^{2}$ for precipitation. The LSS-induced range in the modelled climate is of similar magnitude to the climate change projection estimates for the region, which highlights the importance of carefully selecting a land surface scheme in the regional climate simulations.
\end{abstract}

Keywords Land surface schemes $\cdot$ WRF $\cdot$ Regional climate model $\cdot$ Sensitivity $\cdot$ MENA

\section{Introduction}

The climate of the Middle East and North Africa (MENA) region is characterized by high temperatures and dryness, which have increased in the recent past and are projected to continue increasing in the future, mainly due to anthropogenic greenhouse gases (Lelieveld et al. 2012; Zittis et al. 2016; Lelieveld et al. 2016; Zittis et al. 2019). The projected changes are likely to adversely affect natural ecosystems and society in different sectors such as public health, agriculture, and energy production (Lelieveld et al. 2012; Constantinidou et al. 2016; Zachariadis and Hadjinicolaou 2014).

Katiana Constantinidou

k.constantinidou@cyi.ac.cy

1 The Cyprus Institute, 2121 Nicosia, Cyprus

2 Department of Atmospheric Chemistry, Max Plank Institute for Chemistry, 55020 Mainz, Germany
Spatially relevant information for regional and national climate change impact studies can be obtained from regional climate models (RCMs) that dynamically downscale the output of global climate models (GCMs) over a limited area of the globe (Giorgi and Gutowski 2015). This process is affected by different sources of uncertainty related to the concentration pathways and the GCM-generated boundary conditions that force the RCM simulations. Additionally, RCMs have uncertainties related to their representation of dynamical and physical processes and spatial resolution. The increasing need for the application of RCMs requires a thorough understanding of their advantages, limitations, and uncertainties.

Land surface representation is a critical aspect of climate models as it involves the exchange of heat, moisture, and radiation between the ground and the air (Betts 2009). Land-atmosphere feedbacks can influence seasonal to interannual climate variability in transitional climate zones and mid-latitude regions through three main pathways: soil moisture-temperature, soil moisture-precipitation, and vegetation-climate interactions (Seneviratne et al. 2010). For example, changes in land surface properties influence 
the heat and moisture fluxes within the planetary boundary layer and therefore, directly modify cumulus convection and precipitation (Pielke 2001). It has been shown that land surface processes, land-atmosphere interactions, and associated memory effects can modulate the dynamics of the climate system (Seneviratne and Stoeckli 2008; Zittis et al. 2014b).

Representation of these links in climate simulations is done by using land surface schemes (LSS), which have been gradually improved over the last years (Sellers et al. 1997; Pitman 2003). Among LSSs, there are substantial differences in the level of complexity of the way that various processes are parametrized. However, insufficient understanding and incorporation of the various land-atmosphere feedbacks contribute to uncertain GCM projections (e.g., (Cheng et al. 2017; Lin et al. 2017; Sippel et al. 2017)). Also, as argued in the RCM -based study by Davin et al. (2016), there is a lack of formal evidence that the use of LSS has translated into an overall better climate model performance. Therefore, more systematic evaluations of LSSs coupled with RCMs are necessary in order to examine the relationship between the realism of land surface processes representation and the overall climate model performance. Some organized assessments have recently occurred within the Coordinated Regional Climate Downscaling Experiment (CORDEX) ${ }^{1}$ for the European and African domains (Knist et al. 2017; Soares et al. 2019).

For the MENA domain ${ }^{2}$, there has been an effort recently in investigating the effects of model physics on the simulated climate, especially as part of RCM optimization within the CORDEX, mainly focusing on convection, atmospheric boundary layer, microphysics, and radiation (Zittis et al. 2014a; Bucchignani et al. 2016; Almazroui et al. 2016b; Zittis and Hadjinicolaou 2017). The only study for this region investigating the effects of more than one LSS is undertaken by Almazroui (2016a), who employed the BATS and CLM schemes in RegCM4 RCM and found that CLM results in a much drier climate than with BATS.

In this work, the MENA climate is simulated using the Weather Research and Forecasting (WRF) regional climate model, and its sensitivity due to different land surface schemes is explored and quantified. Six experiments were performed driven by ERA-Interim reanalyses. Due to the high computational cost of some of the tested LSSs and the extended coverage of the MENA-CORDEX domain, we have configured the model at a horizontal resolution of 50 $\mathrm{km}$ (the same as in Almazroui (2016a) and Davin et al. (2016)), while our simulations have a duration of 10 years

\footnotetext{
${ }^{1}$ http://www.cordex.org

${ }^{2}$ http://mena-cordex.cyi.ac.cy/
}

(2000-2010). Four different LSSs (described in section 2.2) are used: Noah, NoahMP (with dynamic vegetation option off and on), CLM, and RUC (with six and nine soil layers). We compare key surface climate, radiation, and turbulent flux variables and show to what degree the choice of LSS affects the modelled climate. The closure of the surface energy balance in WRF under each scheme is also examined and an implied climate sensitivity based on the surface climate response on the perturbed energy balance due to the different LSS is derived.

\section{Data and methodology}

The Weather Research and Forecasting (WRF) model, a mesoscale numerical weather prediction system, is used in this study as a regional climate model (Salathe et al. 2010; Chotamonsak et al. 2011; Nikulin et al. 2012; Soares et al. 2012; Warrach-Sagi et al. 2013; Zittis et al. 2014a; Katragkou et al. 2015; Zittis and Hadjinicolaou 2017; Fita et al. 2019). WRF is a non-hydrostatic model with numerous options for physical parameterizations suitable for applications across scales varying from meters to thousands of kilometers. The model incorporates advanced representations of cloud microphysics and land surface dynamics to simulate the interactions between atmospheric processes like precipitation and land surface characteristics (Salathè et al. 2010).

\subsection{Model setup}

The WRF model version 3.8.1 is used for the simulations over the MENA region with a horizontal resolution of $0.44^{\circ}$ $(\approx 50 \mathrm{~km})$ and 30 vertical levels, according to the CORDEX guidelines for this domain (Giorgi et al. 2009). Our choice of horizontal resolution $(50 \mathrm{~km})$, which determines the model ability to resolve topography and hence affects the LSS working, is the same as in other RCM sensitivity studies to land surface parametrizations (Almazroui 2016a; Davin et al. 2016). The model configuration employed here follows the suggested one for climate applications in this region by Zittis et al. (2014a) and Zittis and Hadjinicolaou (2017). The setup of the model includes the Yonsei University (YSU) PBL (Planetary Boundary Layer) scheme, the Kain-Fritsch (KF) cumulus scheme, the WSM6 cloud microphysics scheme, and RRTMG scheme for long- and short- wave radiation parameterizations. This configuration is the same for all simulations performed in this study except for the land surface scheme (LSS). Four different LSSs are used here, from the eight options that are available in WRF V3.8.1 (shown in Fig. 1). These are the Noah, NoahMP, CLM, and RUC (a more detailed description follows in the next subsection). 
Fig. 1 Results from the WRF Physics Use Survey (August 2015) regarding land surface model choices. Here, the absolute frequency regarding the users' preference is shown (360 WRF users answered). From: www2.mmm.ucar.edu/wrf/wrf_physics_survey.pdf

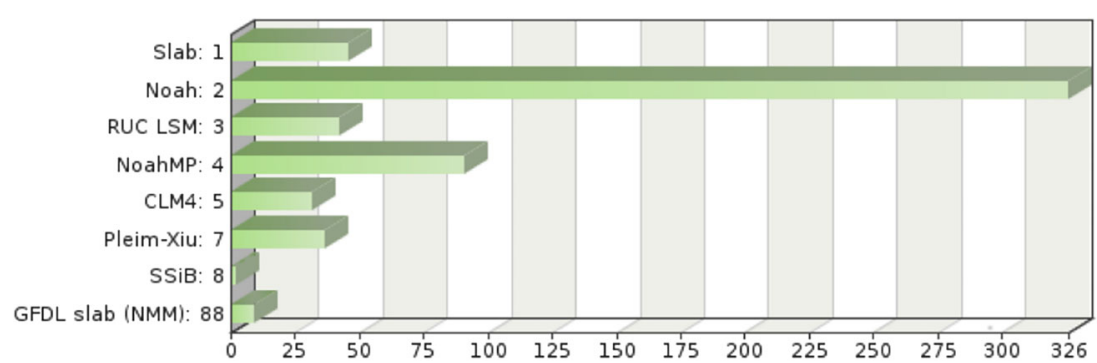

\subsection{Land surface schemes}

The summary listing of the main characteristics of the four LSS used reveals the level of complexity (Table 1). In Fig. 1, the results from the WRF Physics Use Survey (contacted in August 2015) regarding the land surface schemes' choices of 360 WRF users are shown. Noah is a stand-alone, uncoupled, 1-D column version used to execute single-site land surface simulations (Mitchell et al. 2005) and is the most commonly used LSS in the WRF modelling community (as shown in Fig. 1). It appears to be the simplest of the four schemes. The whole grid box is considered as one combined surface layer associated with four vertical levels of soil, one bulk snow layer, and the surface parameters are derived from look-up tables. Its advanced version, NoahMP (multiphysics), uses multiple options for key land-atmosphere interaction processes. It has three snow layers and four soil levels, a sub-division of grid cells into vegetation and soil, and a dynamic vegetation option (Niu et al. 2011). The Community Land Model (CLM) includes a sophisticated treatment of biogeophysics, hydrology, biogeochemistry, and dynamic vegetation (Oleson et al. 2010; Lawrence et al. 2011; Kim et al. 2016). The Rapid Update Cycle (RUC) land surface scheme was originally developed to provide accurate lower boundary conditions, focusing on short-range aviation and severe weather prediction (Benjamin et al. 2004) but has recently been extended to wider geographical application and implemented in WRF as a land surface scheme option. CLM and RUC include the most detailed representation of snow (five layers in CLM and two layers in RUC), soil (up to ten and nine vertical levels respectively), surface parameters (from satellitebased datasets), and vegetation physics, and therefore can be considered as the most elaborated of the four schemes.

\subsection{Numerical experiments}

In order to study the sensitivity of the model climate to different LSSs, six different numerical integrations (listed in Table 2) were performed for the 10-year period 20002010. The ERA-Interim reanalysis data set (Dee et al.
2011) was used to provide initial and boundary conditions, with the latter being updated every $6 \mathrm{~h}$. The elevenmonth period of January to November 2000 was considered as spin-up time and was therefore excluded from the analysis, which is made for the period December 2000 November 2010.

Noah is the most commonly used LSS among the WRF community, and it is therefore considered as the reference scheme (run 1) in the subsequent analysis. NoahMP, an advanced Noah scheme, has a dynamic vegetation model option that can be turned off or on. When this option is off, the monthly leaf area index (LAI) is prescribed for various vegetation types and the vegetation greenness fraction (GVF) comes from monthly GVF climatological values, while when it is turned on, LAI and GVF are predicted using a dynamic leaf model. Runs 2 and 3 are carried out using the NoahMP with the dynamic vegetation option off and on, respectively. The CLM scheme is used in experiment 4. The RUC scheme is used for the last two runs (5 and 6) that only differ in the number of soil layers (six and nine, respectively). Experiments 3, 4, 5, and 6, due to their more detailed treatment of land processes, can be considered as the most "advanced" simulations compared to runs 1 and 2.

\subsection{Analysis: variables and methods}

Several model output variables are analyzed: surface climatic parameters (mean 2-m air temperature, total precipitation, land surface temperature, soil moisture); radiative fluxes (short-wave upward radiation,long-wave upward radiation, net radiation); turbulent fluxes (sensible, latent and ground heat fluxes).

Annual climatologies are derived from the monthly mean time series of the above-mentioned climatic parameters. The 10-year climatologies (average for the period of December 2000-November 2010) are calculated and plotted for the MENA region (for the Noah reference LSS as absolute values and the other schemes as their difference from the Noah).

Additionally, a more spatially focused analysis is performed based on the area averages of twelve sub-regions within the MENA domain, representative of different 
Table 1 Main characteristics and comparison of the Noah, NoahMP, CLM 4.0, and RUC land surface schemes in WRF version 3.8.1

\begin{tabular}{|c|c|c|c|c|}
\hline $\begin{array}{l}\text { LSM } \\
\text { characteristics }\end{array}$ & Noah & NoahMP & CLM & RUC \\
\hline $\begin{array}{l}\text { Prognostic } \\
\text { levels } \\
\text { vertical }\end{array}$ & $\begin{array}{l}\text { Soil }=4 \\
\text { snow }=1\end{array}$ & $\begin{array}{l}\text { Soil }=4 \\
\text { snow }=3\end{array}$ & $\begin{array}{l}\text { Soil }=10 \\
\text { snow }=5\end{array}$ & $\begin{array}{l}\text { Soil }=9 \\
\text { snow }=2\end{array}$ \\
\hline $\begin{array}{l}\text { Temperature and } \\
\text { energy balance } \\
\text { calculations }\end{array}$ & $\begin{array}{l}\text { Over a } \\
\text { combined } \\
\text { surface layer } \\
\text { of vegetation } \\
\text { and snow }\end{array}$ & $\begin{array}{l}\text { Separate } \\
\text { vegetation } \\
\text { canopy } \\
\text { and ground }\end{array}$ & $\begin{array}{l}\text { Separate } \\
\text { vegetation } \\
\text { canopy } \\
\text { and ground }\end{array}$ & $\begin{array}{l}\text { Separate } \\
\text { vegetation } \\
\text { canopy } \\
\text { and ground }\end{array}$ \\
\hline $\begin{array}{l}\text { Radiation } \\
\text { fluxes }\end{array}$ & $\begin{array}{l}\text { Considers the } \\
\text { whole grid } \\
\text { as one }\end{array}$ & $\begin{array}{l}\text { 2-stream } \\
\text { radiation } \\
\text { transfer } \\
\text { scheme }\end{array}$ & $\begin{array}{l}\text { 2-stream } \\
\text { radiation } \\
\text { transfer } \\
\text { scheme }\end{array}$ & $\begin{array}{l}\text { Separation } \\
\text { of grid- } \\
\text { box as } \\
\text { vegetated } \\
\text { and ground }\end{array}$ \\
\hline Soil hydrology & $\begin{array}{l}\text { Relevant } \\
\text { equations } \\
\text { solved } \\
\text { over } \\
4 \text { soil } \\
\text { layers }\end{array}$ & $\begin{array}{l}\text { Simple } \\
\text { groundwater } \\
\text { model, taking } \\
\text { into account } \\
\text { an unconfined } \\
\text { aquifer added } 2 \mathrm{~m} \\
\text { below the bottom } \\
\text { of soil layers }\end{array}$ & $\begin{array}{l}\text { Groundwater } \\
\text { model } \\
\text { Richard's } \\
\text { equations } \\
\text { solved for } \\
\text { multi-layer } \\
\text { soil column }\end{array}$ & $\begin{array}{l}\text { Relevant } \\
\text { equations } \\
\text { solved over } \\
\text { multi- layer } \\
\text { soil column }\end{array}$ \\
\hline $\begin{array}{l}\text { Subgrid-scale } \\
\text { heterogeneity }\end{array}$ & & $\begin{array}{l}\text { Semi-tile } \\
\text { approach }\end{array}$ & $\begin{array}{l}\text { Tile } \\
\text { approach }\end{array}$ & $\begin{array}{l}\text { Tile approach } \\
\text { (17 PFTs) } \\
\text { (seasonal } \\
\text { variations } \\
\text { included) }\end{array}$ \\
\hline $\begin{array}{l}\text { Surface } \\
\text { parameters }\end{array}$ & $\begin{array}{l}\text { LAI and GVF } \\
\text { from look-up } \\
\text { tables }\end{array}$ & $\begin{array}{l}\text { Short-term } \\
\text { dynamic } \\
\text { vegetation } \\
\text { option } \\
\text { (LAI and GVF } \\
\text { when turned on) }\end{array}$ & $\begin{array}{l}\text { MODIS-based } \\
\text { data (LAI, PFT } \\
\text { distribution) } \\
\text { IGBP Global } \\
\text { Soil Data } \\
\text { Task } 2000 \\
\text { (for soil texture } \\
\text { and soil organic } \\
\text { matter with } \\
\text { vertical profile }\end{array}$ & $\begin{array}{l}\text { MODIS-based } \\
\text { (FPAR/ } \\
\text { LAI data) }\end{array}$ \\
\hline
\end{tabular}

geographic areas and climatic regimes (Section 3.2). These are western, central, and eastern Mediterranean, Balkans, Anatolia, Mesopotamia, Persian region, Arabian Gulf, Arabian peninsula, Egypt, Libya, and Maghreb, as shown in Fig. 2. The sub-regional analysis is made for the three basic surface climatic parameters, 2-m air and land surface temperature and precipitation and the metrics used for this analysis are mean, median, and other quantiles in boxer-and-whisker plots (Crawley 2015), and coefficient of variation. The coefficient of variation is defined as the standard deviation divided by the mean (von Storch and Zwiers 1999). 
Table 2 Description of the six performed experiments

\begin{tabular}{lll}
\hline $\begin{array}{l}\text { Experiment } \\
\text { number }\end{array}$ & Land surface scheme & $\begin{array}{l}\text { Number of soil } \\
\text { layers }\end{array}$ \\
\hline Run 1 & Noah & 4 \\
Run 2 & NoahMP \\
& dynamic vegetation = OFF & 4 \\
Run 3 & NoahMP & 4 \\
Run 4 & CLnamic vegetation = ON & \\
Run 5 & RUC & 10 \\
Run 6 & RUC & 6 \\
\hline
\end{tabular}

The following equation is used to estimate the effect of the different land surface schemes on the modelled land surface energy balance:

$\frac{d H}{d t}=R_{n}-\lambda E-S H-G$

where $\frac{d H}{d t}$ is the change of energy $H$ in the considered surface soil layer, $R_{n}$ is the net radiation, $\lambda \mathrm{E}$ is the latent heat flux, $\mathrm{SH}$ is the sensible heat flux, and $G$ is the ground heat flux at the surface (from (Seneviratne et al. 2010), Section 3, Equation 6).

The inferred WRF model climate sensitivity to the land surface schemes can be calculated by applying the concept developed for the Earth's climate system (Hartmann 2016). The model-based surface climate sensitivity for the MENA domain, labelled as $\lambda$, may be then defined as

$\lambda=\frac{\Delta\left(T_{a}, T_{l}, \operatorname{Pr}\right)}{\Delta\left(\frac{d H}{d t}\right)}$

where $\Delta\left(T_{a}, T_{l}, \operatorname{Pr}\right)$ is the perceived surface climate response (i.e., change in air and land temperature, and precipitation) of the WRF model to the forcing of the "perturbed" surface energy balance $\Delta\left(\frac{d H}{d t}\right)$ induced by the different LSSs against the default Noah scheme, which is taken as reference.

\section{Results}

\subsection{Domain-wide spatial differences}

For this subsection, annual climatologies (for the period December 2000 to November 2010) of ten key climatic variables are presented in 6-panel figures with the top left panel showing the Noah run (absolute values), and the rest of the panels including the other five experiments (as differences relative to Noah).

In Fig. 3 for mean 2-m air temperature, it is shown that in many areas in the $15-30^{\circ} \mathrm{N}$ band (including Sahara), all five schemes simulate higher values (in the range of $1-2.5^{\circ} \mathrm{C}$ ) compared to Noah. CLM, in particular, is much warmer over almost the whole southern part of the domain, including the Arabian peninsula, with distinct differences $\left(\Delta \mathrm{T}>3.5^{\circ} \mathrm{C}\right)$ over Egypt (along the Nile River and its delta). The smallest positive differences appear within the $20-30^{\circ} \mathrm{N}$ band in northern Africa when comparing RUC (with six and nine soil layers) with Noah. For the rest of the MENA domain, all schemes appear to be generally colder than the reference Noah.

Land surface temperature is examined in Fig. 4. Looking at the output of the simulation performed by Noah, higher absolute values than the air temperature are simulated. There is a connection between the land surface temperature and upward long-wave radiation (Fig. 5), which is demonstrated by the similar patterns of these two variables in the absolute value maps of the Noah simulation. Looking at the differences between the five schemes and Noah (rest of Fig. 4), it is evident that the latter is relatively warmer (widespread negative values across the
Fig. 2 Model orography (at $50-\mathrm{km}$ grid size) of the MENA domain used in the analysis and the 12 sub-regions (Anatolia, Balkans, western, central and eastern Mediterranean, Mesopotamia, Persian region, Arabian Gulf, Arabian peninsula, Egypt, Libya and Maghreb)

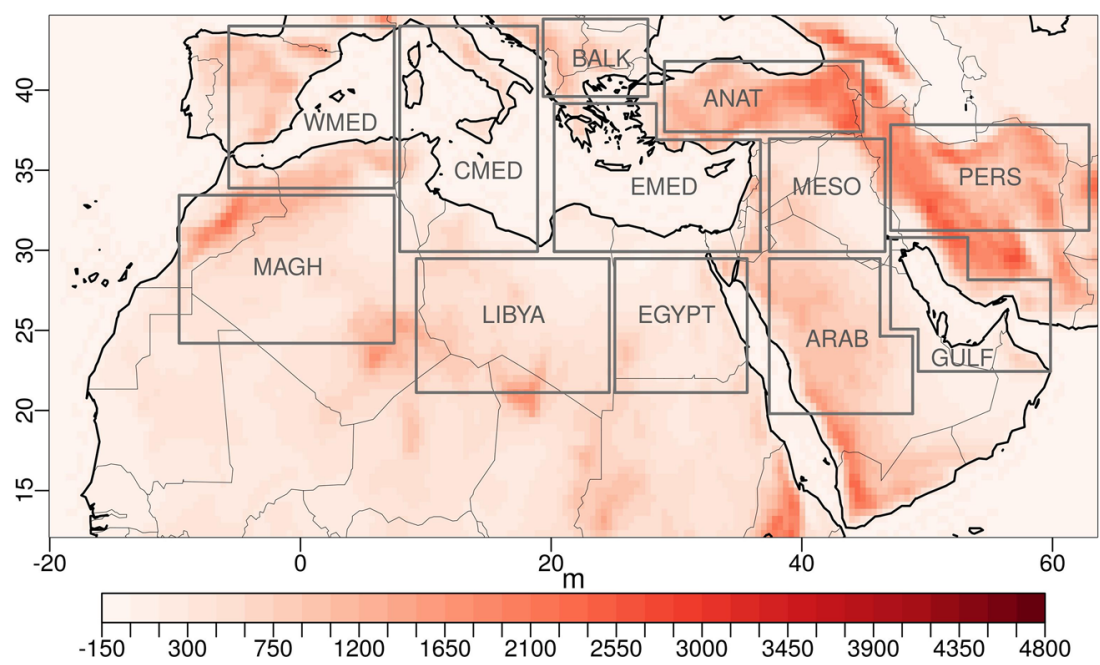



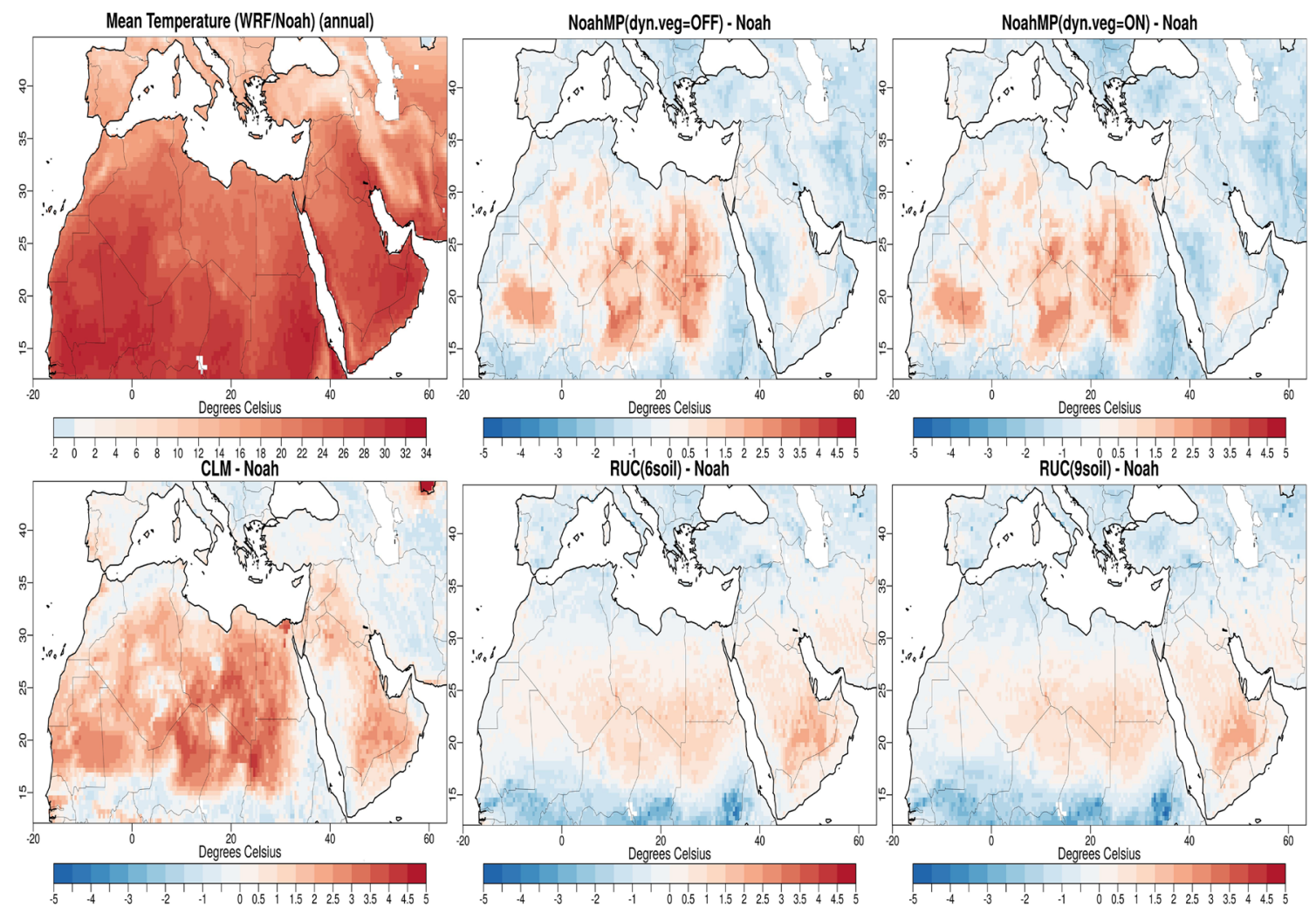

Fig. 3 Annual air temperature (Tmean) averaged for December 2000-November 2010 simulated by WRF with the Noah scheme (top left) and its difference from the runs with the NoahMP (dyn. veg.= off and on), CLM, RUC (6 and 9 soil layers) schemes
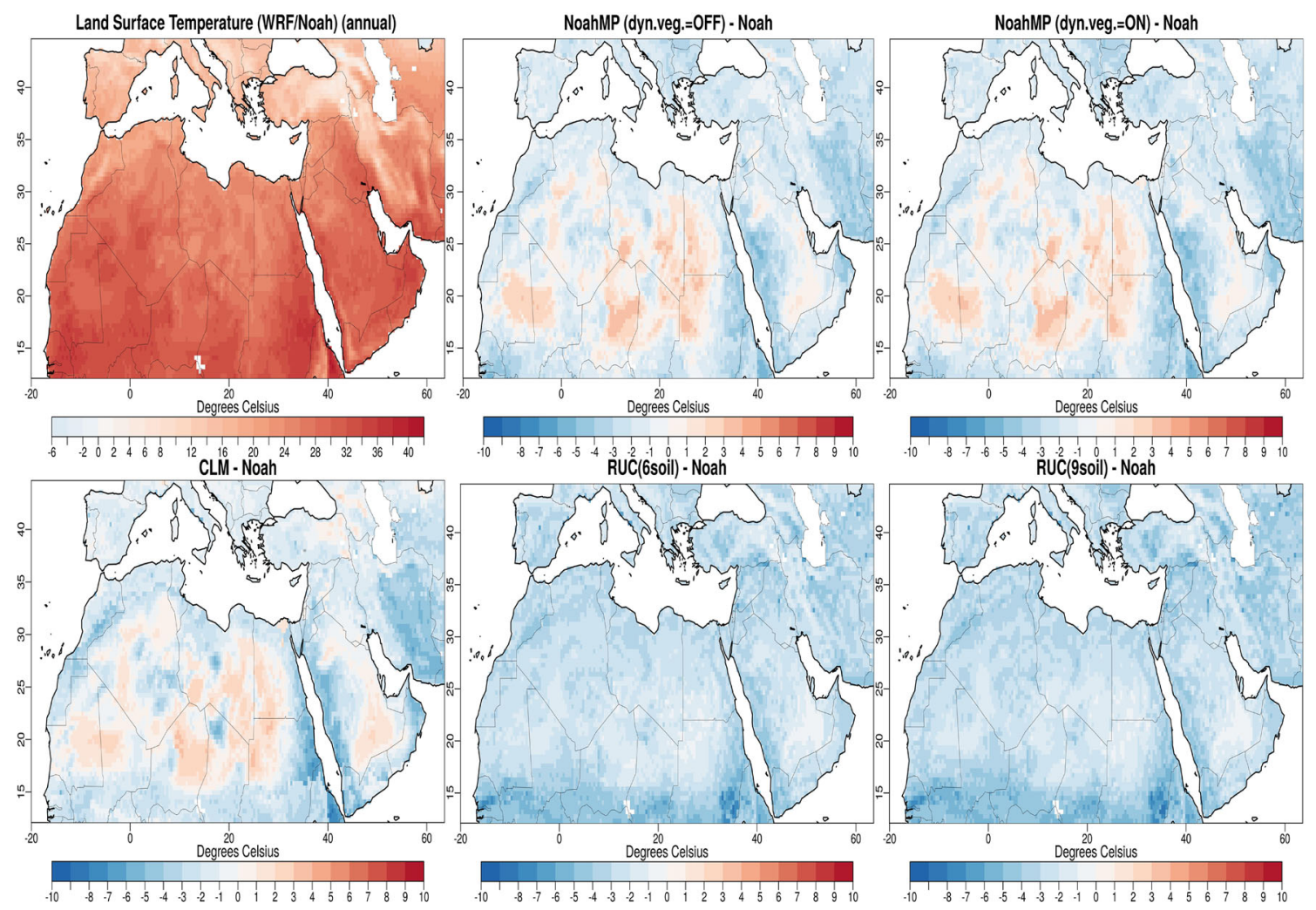

Fig. 4 Annual land surface temperature (LST) averaged for December 2000-November 2010 simulated by WRF with the Noah scheme (top left) and its difference from the runs with the NoahMP (dyn. veg.= off \& on), CLM, RUC (6 and 9 soil layers) schemes 

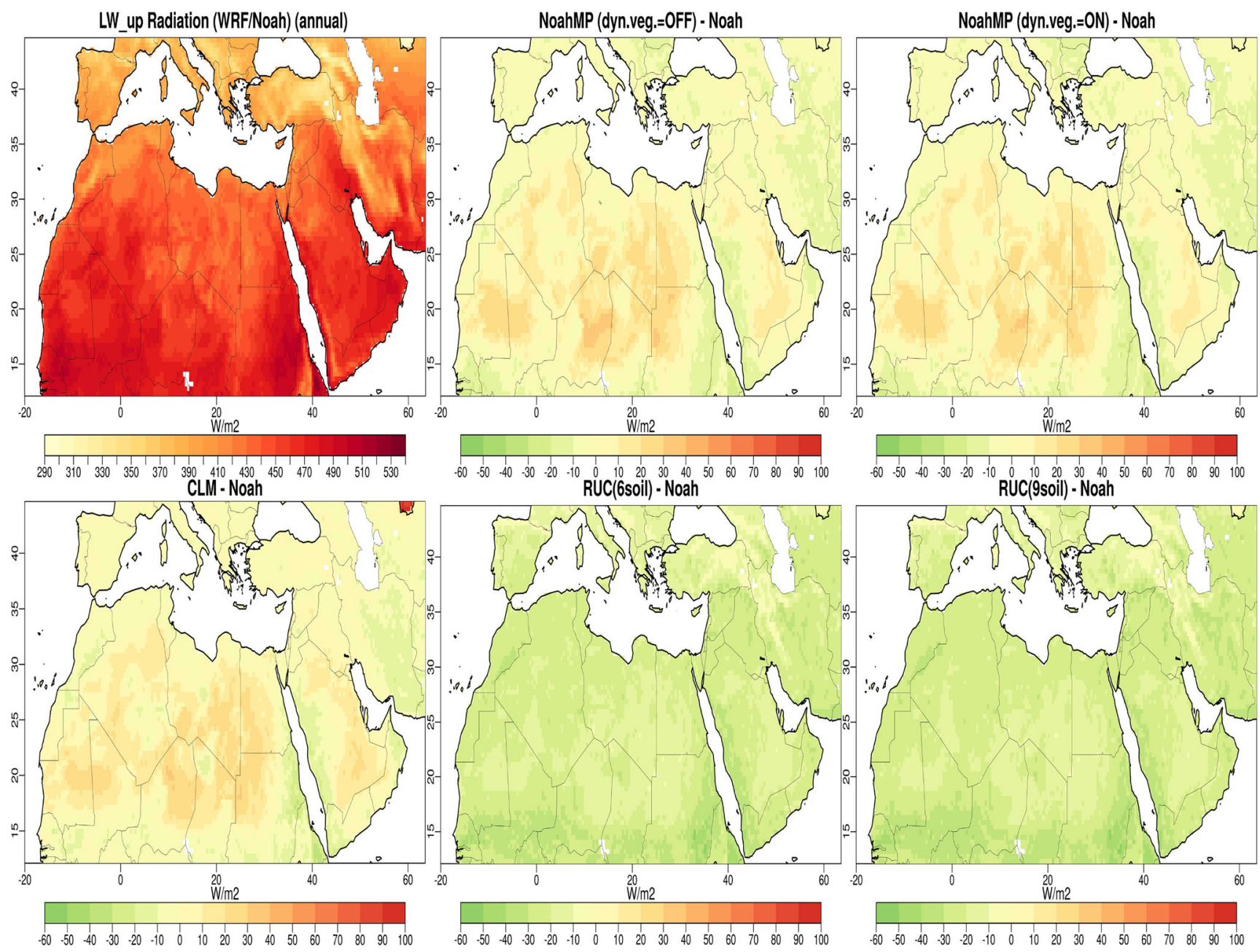

Fig. 5 Annual long-wave upwelling radiation (LW_up) averaged for December 2000-November 2010 simulated by WRF with the Noah scheme (top left) and its difference from the runs with the NoahMP (dyn. veg.= off and on), CLM, RUC (6 and 9 soil layers) schemes

domain), with the exception of certain areas in NoahMP (both options) and CLM, which are warmer by 3 to 4 ${ }^{\circ} \mathrm{C}$ than Noah, mainly in the region of the Sahara desert. Similar patterns are found for differences between the five schemes and Noah of the short-wave upward radiation shown in Fig. 6. NoahMP and CLM include shading effects through a two-stream canopy radiation transfer scheme, which may explain some of the differences. The canopy and the ground surface temperatures are computed separately, also considering canopy gaps and calculate fractions of sunlit and shaded leaves along with their absorbed solar radiation (Niu et al. 2011; Oleson et al. 2010), while Noah only considers the whole grid cell. Hence, in the presence of vegetation and canopy, radiation can be trapped near the surface layer, which leads to higher land surface temperature and less reflected short-wave radiation simulated by NoahMP and CLM in comparison with the reference Noah scheme (which does not account for this effect).
The long-wave upwelling radiation (LW-up) is presented in Fig. 5. As previously mentioned, LW-up radiation on the Noah map (absolute values) has similar patterns with land surface temperature, with generally higher values at the southern part of the domain, which are decreasing northward. The comparison of the other LSS runs with the reference scheme illustrates that NoahMP (with the dynamic vegetation option turned off and on) together with CLM, simulate higher (by 10-30 $\mathrm{W} / \mathrm{m}^{2}$ ) long-wave upward radiation in parts of northern Africa and in particular the Sahara region. Negative differences $\left(10-30 \mathrm{~W} / \mathrm{m}^{2}\right)$ over the northern part of the domain are obtained with both NoahMP options and CLM, which also extend over the eastern part of the domain and along the Red Sea. On the other hand, RUC shows negative differences compared to the reference LSS (Noah), implying lower simulated long-wave emission from the surface.

In Fig. 6, the annual climatology of short-wave upward radiation (SW-up) simulated by Noah indicates that areas 

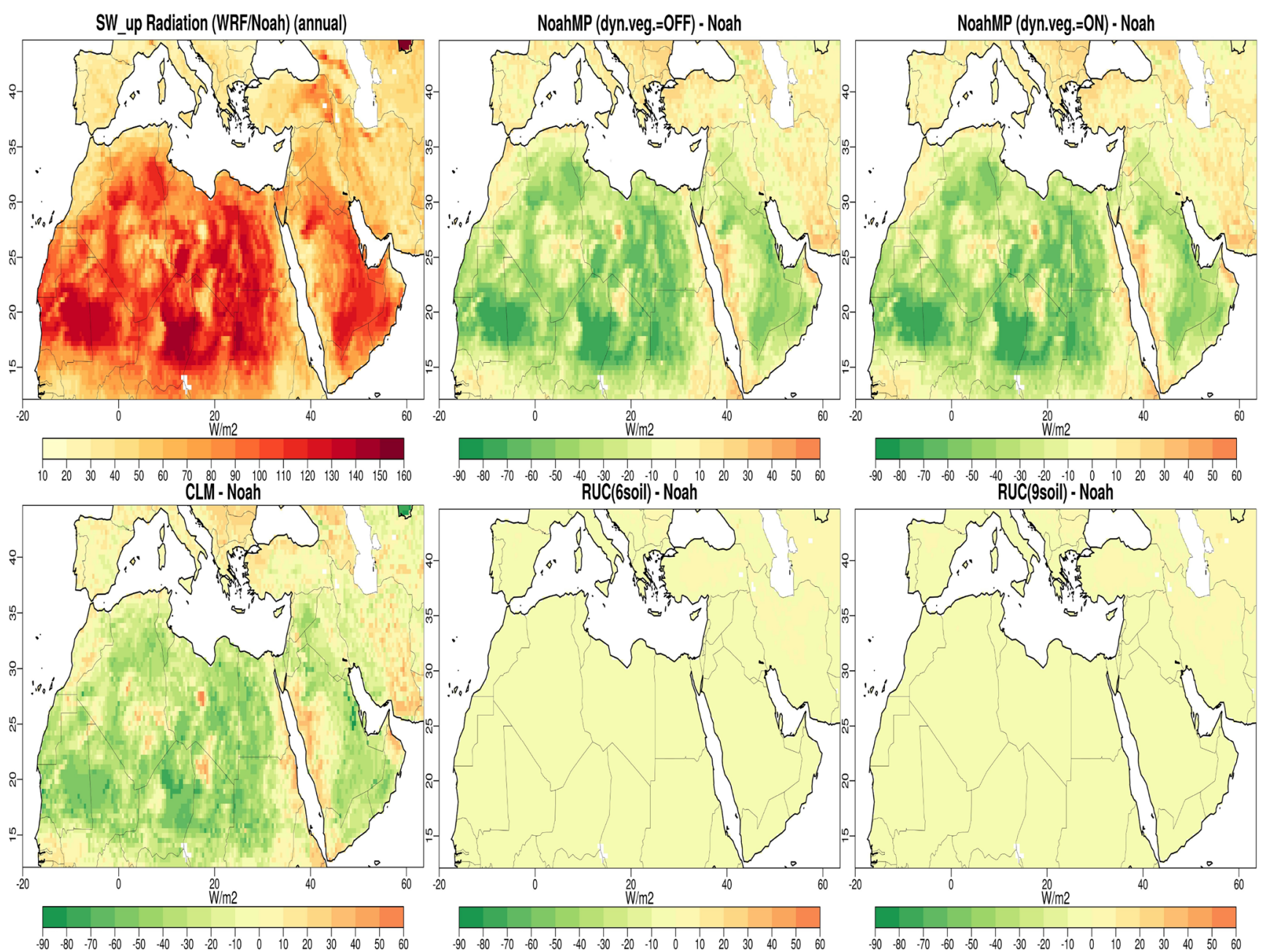

Fig. 6 Annual short-wave upward radiation (SW_up) averaged for December 2000-November/2010 simulated by WRF with the Noah scheme (top left) and its difference from the runs with the NoahMP (dyn. veg.= off and on), CLM, RUC (6 and 9 soil layers) schemes

in the Sahara and the Arabian Peninsula with the largest values of this parameter coincide with areas of low sensible heat flux (presented in Fig. 7), demonstrating the link between reduced surface heating and sensible heat flux with higher short-wave radiation reflection (and vice versa). SW-up can be also related to the soil moisture (shown in Fig. 8) that can affect the albedo. Comparing the Noah absolute values (top left maps in Figs. 6 and 8), regions of higher reflected SW radiation coincide with areas of very low soil moisture. This can be explained by the fact that brighter surfaces such as bare soil or desert with low soil moisture have a higher albedo. Focusing on the differences of the schemes from Noah (the rest of Fig. 6), one can see that the two options of NoahMP underestimate shortwave upward radiation in comparison with the reference over the southern half of the domain, with peak negative differences of around $80-90 \mathrm{~W} / \mathrm{m}^{2}$. Lower values than Noah are also simulated by CLM over the same region, with lower negative differences between $50-60 \mathrm{~W} / \mathrm{m}^{2}$. Across both land sides adjacent to the Red Sea, these three schemes have positive differences, with NoahMP (runs 2 and 3) exhibiting the highest deviations $\left(30-40 \mathrm{~W} / \mathrm{m}^{2}\right)$. Both runs of RUC simulate similar upward SW to the Noah ones, resulting in negligible differences.

We next look at the sensible heat flux in Fig. 7. In comparison to Noah, the other five schemes simulate higher sensible heat over most of the southern part of the MENA domain (except for latitudes southern of $15^{\circ} \mathrm{N}$ ). Further away (both northwards and southwards) from the Sahara desert and the Arabian peninsula, the values obtained by the five LSSs are lower than the ones by Noah. For the easternmost parts of the domain (Iran and Anatolia), both RUC simulations exhibit positive differences of about $50 \mathrm{~W} / \mathrm{m}^{2}$ when compared to Noah, while the differences obtained by NoahMP and CLM are contrary (in the range of -30 to $-50 \mathrm{~W} / \mathrm{m}^{2}$ ). Over most of the northern (European) part of the domain, negative differences are present with all five schemes. All these features closely 

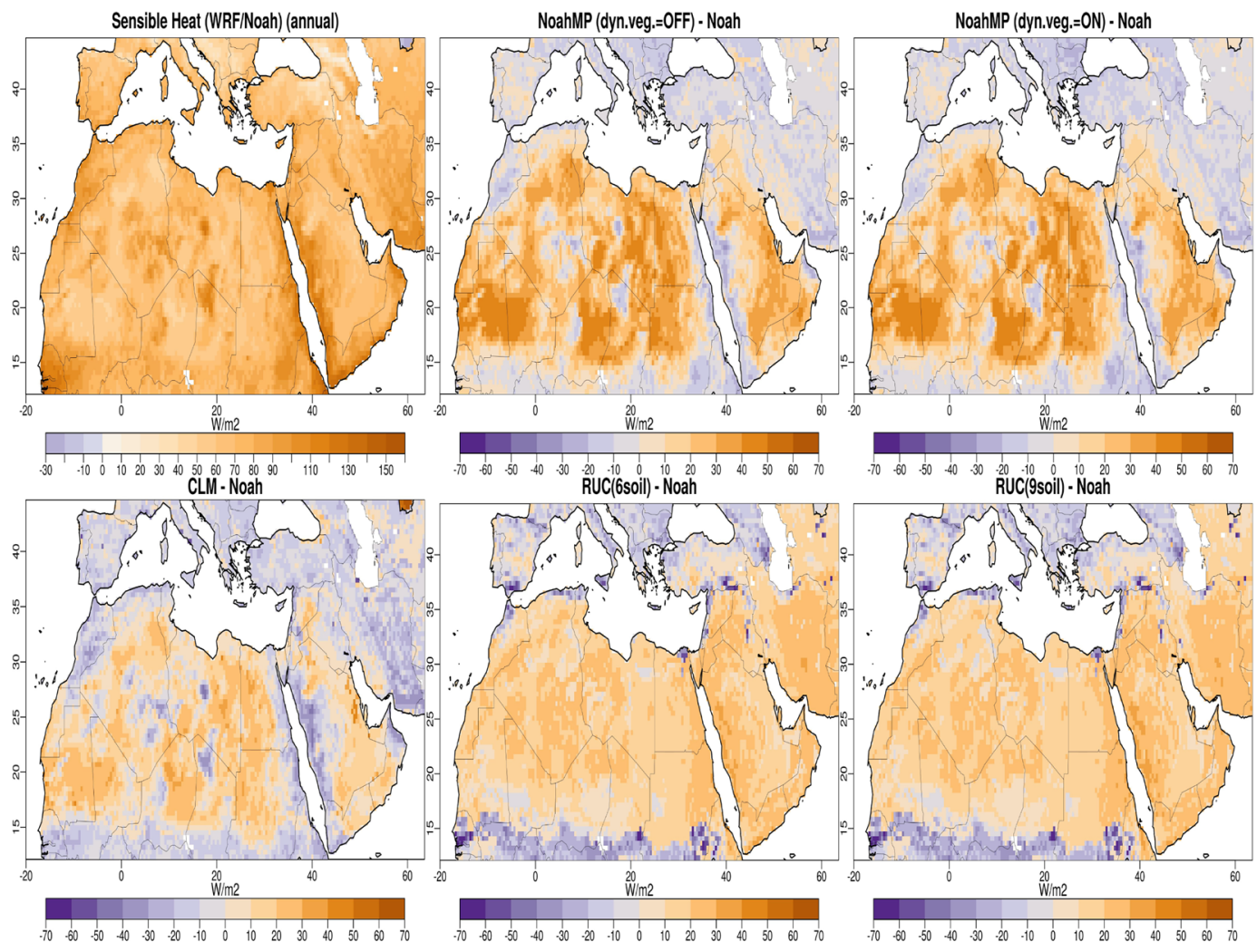

Fig. 7 Annual sensible heat flux averaged for December 2000-November 2010 simulated by WRF with the Noah scheme (top left) and its difference from the runs with the NoahMP (dyn. veg.= off and on), CLM, RUC (6 and 9 soil layers) schemes
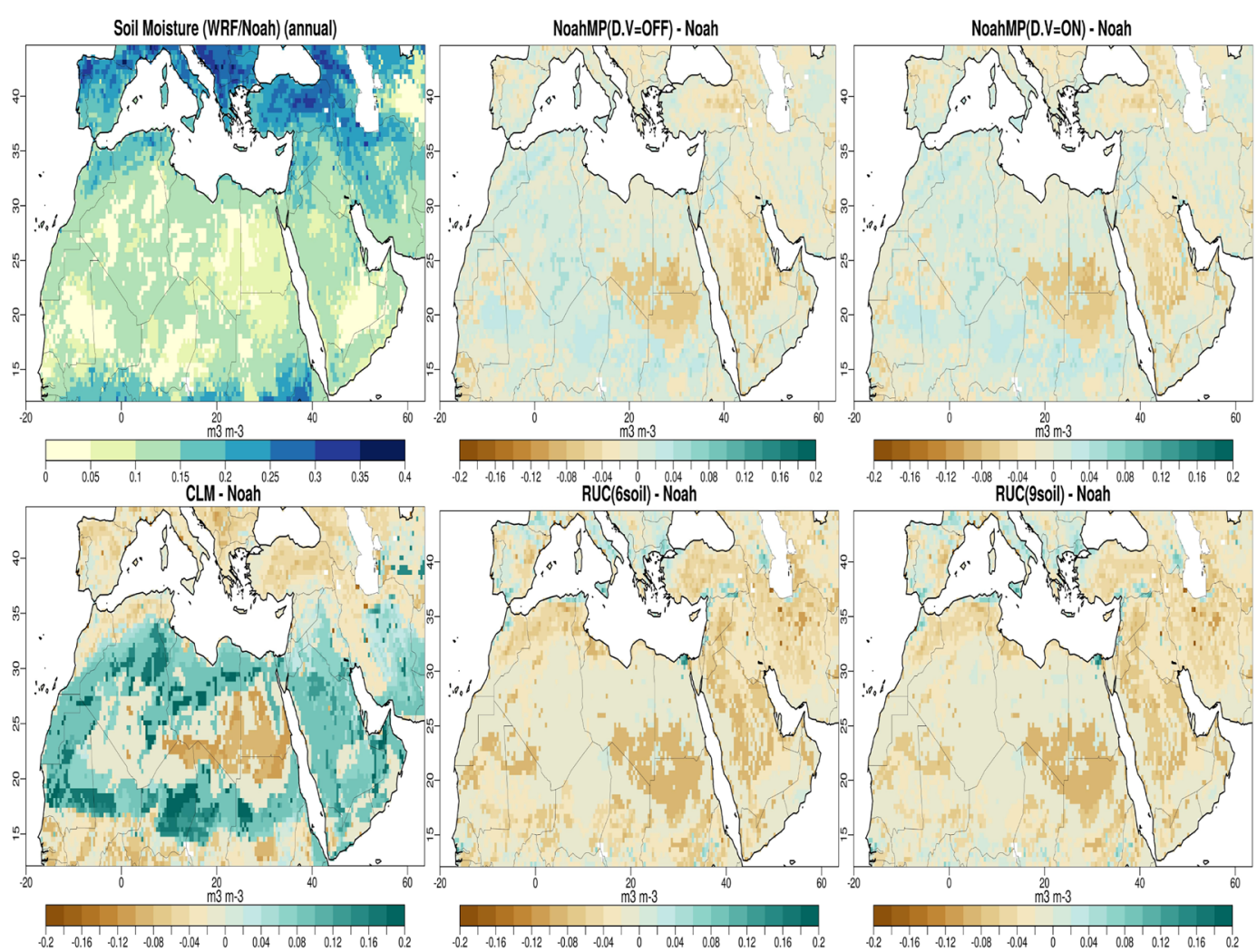

Fig. 8 Annual soil moisture averaged for December 2000-November 2010 simulated by WRF with the Noah scheme (top left) and its difference from the runs with the NoahMP (dyn. veg.= off and on), CLM, RUC (6 and 9 soil layers) schemes 
match the corresponding geographical patterns of air and land temperature shown in Figs. 3 and 4, respectively.

Results for soil moisture are presented in Fig. 8. It was mentioned before that soil moisture is linked to short-wave upward radiation (shown in Fig. 6), and this connection is explained by the albedo of the surface. It can be seen at the Noah absolute values, where areas of the domain with very low soil moisture have high SW-up radiation, indicative of a highly reflective surface. CLM seems to be the land surface scheme that simulates larger amounts of soil moisture compared to Noah, having the highest positive differences among all five comparisons, reaching values of $0.2 \mathrm{~m}^{3} \mathrm{~m}^{-3}$. These are calculated over the southern part of the domain except the Sahara desert, covering parts of Egypt, Sudan, Chad, and Niger, where CLM and the rest of the LSSs simulate less soil moisture than Noah. The two options of NoahMP simulate higher soil moisture than Noah over North Africa, except the Sahara. The same is seen over the coastal areas of the Mediterranean Sea. In the center of the Arabian peninsula, these options simulate lower values than the reference scheme. RUC (with six and nine soil layers) is shown to be drier than Noah in most of the areas of the MENA domain. Over the area around Gibraltar, Italy, the Balkans (except Greece), and the borders of Syria with Turkey, both options of RUC simulate higher soil moisture than the reference LSS.

The annual average monthly precipitation is presented in Fig. 9. Noah computes relatively high annual precipitation over the European and Asian parts of the domain (with distinct maxima over the major mountain ranges) and in the tropical part of the domain, south of $15^{\circ} \mathrm{N}$ (demonstrating the location of the Inter-Tropical Convergence Zone). As water changes phase through evaporation/transpiration, energy is maintained in the atmosphere in the form of latent heat, evident in the similar patterns of the latent heat flux map (Fig. 10). All other simulations compared to Noah in Fig. 9 illustrate wetter conditions, with minor differences of up to $20 \mathrm{~mm}$ over most parts of the domain. Exceptions
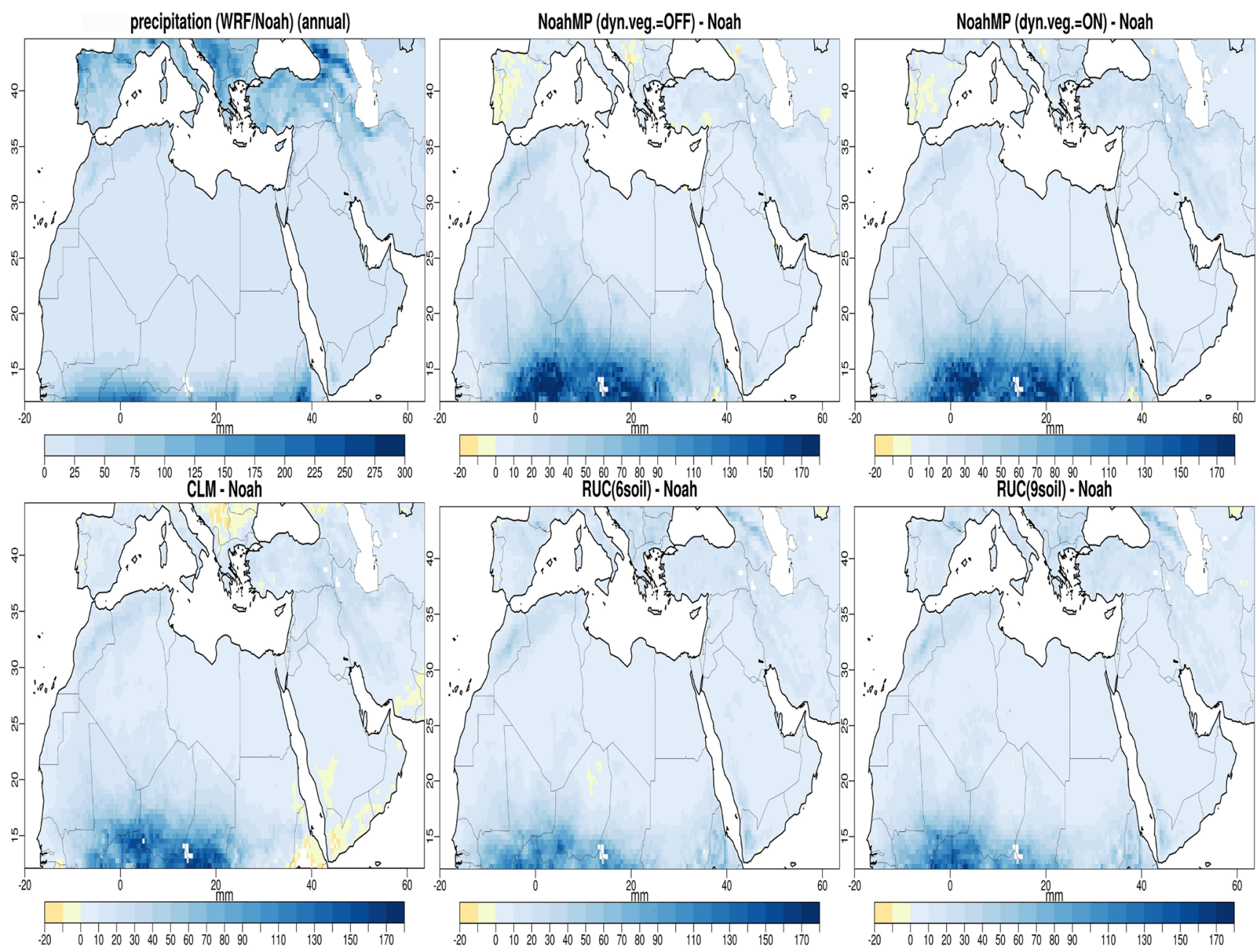

Fig. 9 Annually averaged monthly precipitation climatology for December 2000-November 2010 simulated by WRF with the Noah scheme (top left) and its difference from the runs with the NoahMP (dyn. veg.= off and on), CLM, RUC (6 and 9 soil layers) schemes 


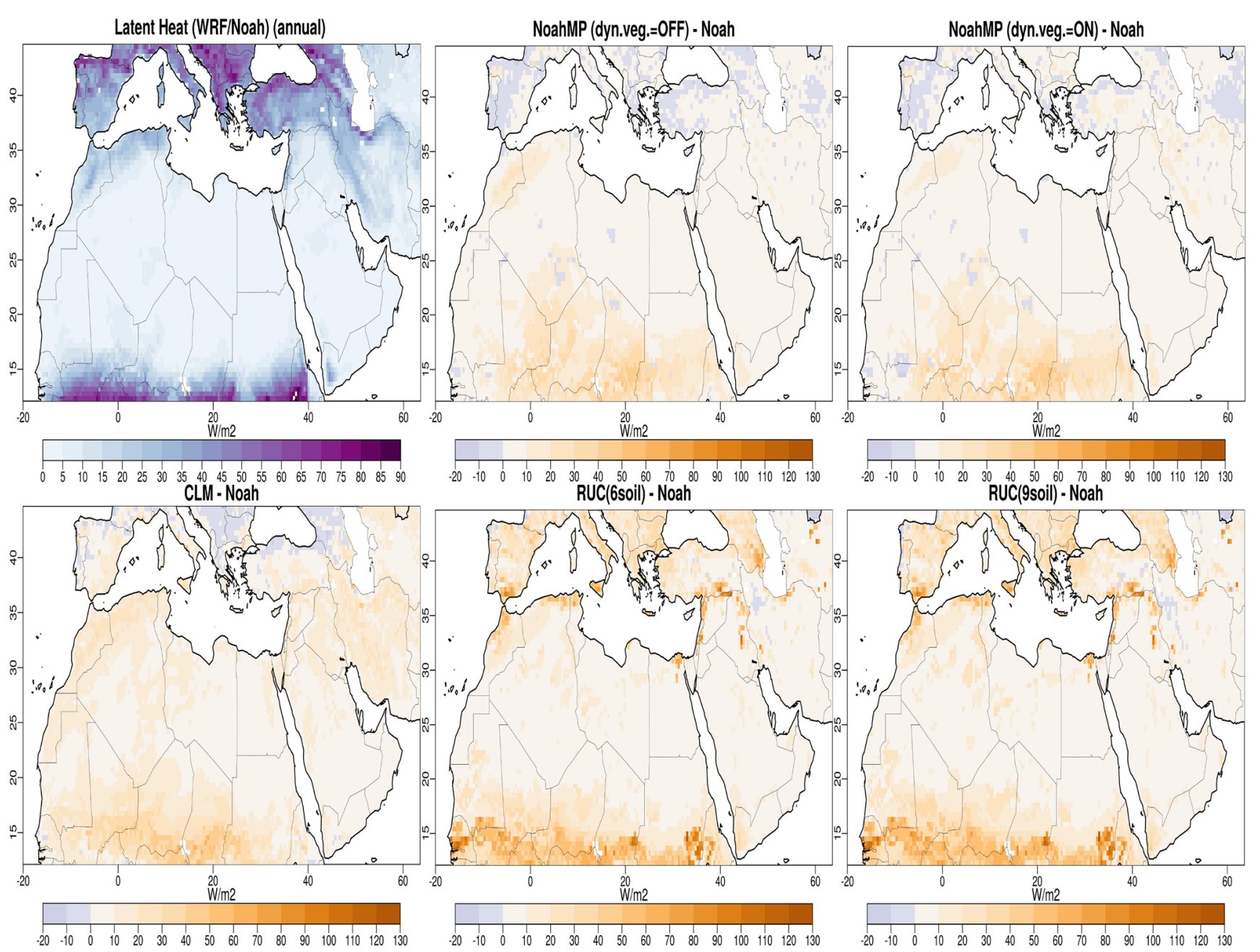

Fig. 10 Annual latent heat flux averaged for December 2000-November 2010 simulated by WRF with the Noah scheme (top left) and its difference from the runs with the NoahMP (dyn. veg.= off and on), CLM, RUC (6 and 9 soil layers) schemes

are the NoahMP runs with dynamic vegetation options off and on, where negative differences are present in Portugal and parts of Spain of around $10 \mathrm{~mm}$, and CLM, which is dryer than Noah with up to $20 \mathrm{~mm}$ over the Balkans. For the areas within latitudes $10-15^{\circ} \mathrm{N}$, all schemes yield differences larger than $100 \mathrm{~mm}$ in comparison with the reference scheme, with RUC (6 layers) having the smallest differences.

Latent heat is presented in Fig. 10, where the Noah scheme simulates a larger latent heat flux over the northern and southernmost parts of the domain. The differences of all five schemes compared to Noah appear positive in most of the areas and are of the order of $10-30 \mathrm{~W} / \mathrm{m}^{2}$, meaning a higher latent heat flux than Noah. In the zone of latitudes below $15^{\circ}$, the two options of RUC simulate higher values for latent heat compared to Noah, up to $90 \mathrm{~W} / \mathrm{m}^{2}$ in some grid boxes. The other schemes also seem to have positive differences against the reference but are less pronounced in terms of spatial distribution and absolute values.
Net radiation (the sum of net short- (downward SW minus upward SW) and net long-wave (downward LW minus upward LW) radiation) is presented in Fig. 11. With the Noah scheme, over the central part of the domain, most of the grid boxes (mainly corresponding to desert or barren land) have low values of net radiation $(<80$ $\mathrm{W} / \mathrm{m}^{2}$ ) indicating enhanced radiative cooling in the cloudfree environment and stronger short-wave reflection due to higher surface albedo. Over the northern and southernmost parts of the domain, radiative cooling is reduced under cloudier skies; therefore, net radiation is much higher (up to $160 \mathrm{~W} / \mathrm{m}^{2}$ ). Over precisely these regions, simulated latent heat flux (shown in Fig. 10) has similarly larger values than the rest of the domain, a spatial signature of high evaporation and transpiration over these wetter and more densely vegetated areas. Comparison of the different schemes to the Noah for net radiation reveals that both options of RUC result in positive differences $(<10-30$ $\mathrm{W} / \mathrm{m}^{2}$ ) over the whole domain. Also, more significant 


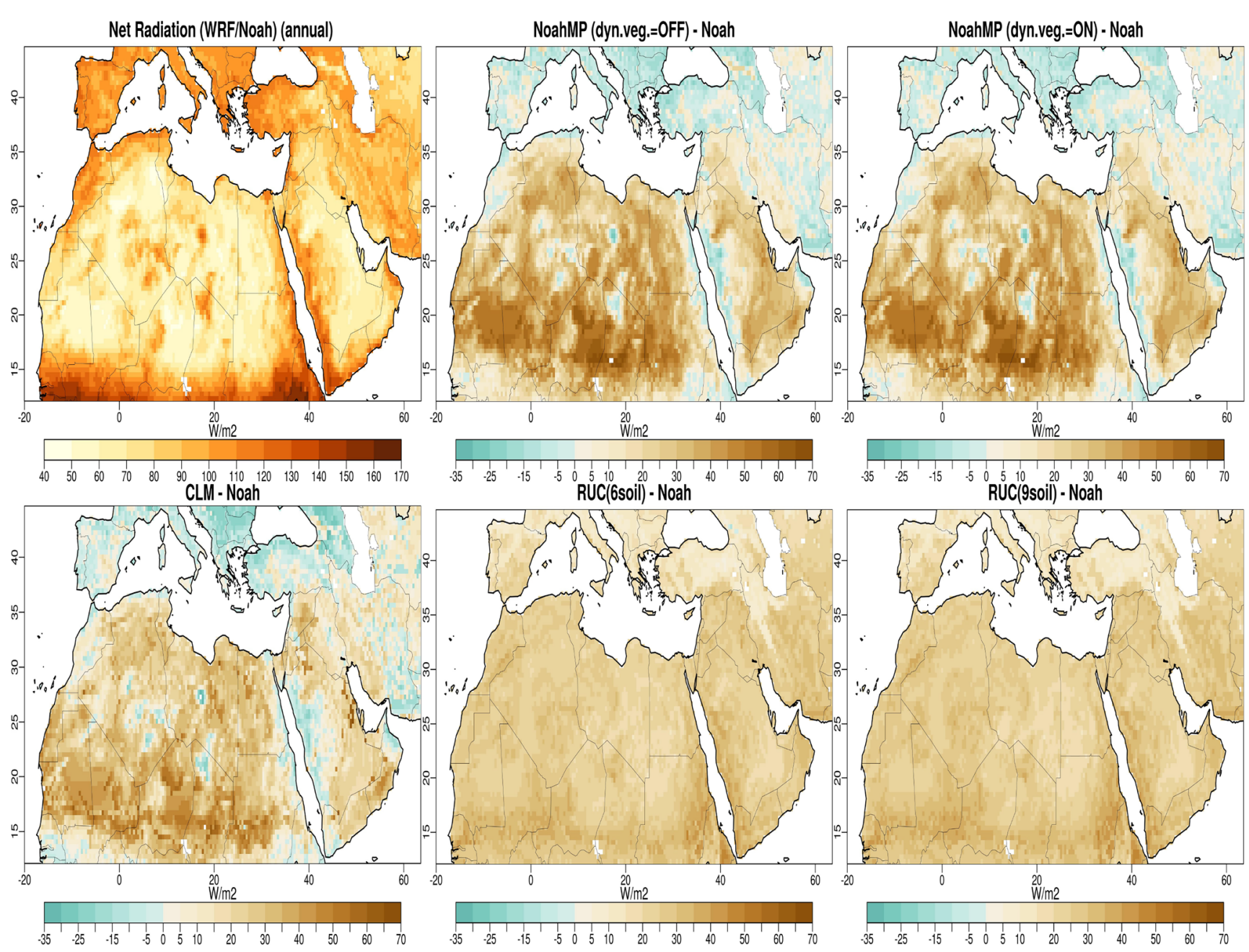

Fig. 11 Annual net radiation averaged averaged for December 2000-November 2010 simulated by WRF with the Noah scheme (top left) and its difference from the runs with the NoahMP (dyn. veg.= off and on), CLM, RUC (6 and 9 soil layers) schemes

positive differences $\left(60-70 \mathrm{~W} / \mathrm{m}^{2}\right)$ are apparent with the NoahMP (both options) and CLM over $15-25^{\circ} \mathrm{N}$ in Africa. These schemes underestimate the Noah net radiation (with CLM simulating the highest negative differences) over the northern and eastern parts of the MENA domain.

Radiative energy exchange at the Earth's surface has another consequence, which is to warm its subsurface. This results from transferring heat from the surface downwards when a temperature gradient exists between the surface and subsurface, expressed by the ground heat flux, presented in Fig. 12. Noah simulates a negative ground heat flux over almost the whole domain, where heat is transferred upwards, except in some areas around $0^{\circ}$ longitude at 15 $25^{\circ} \mathrm{N}$ and over the south-western part of the Arabian peninsula where it is positive (i.e., heat is transferred downward). Regarding the differences with the other schemes, both options of NoahMP simulate higher ground heat flux compared to the reference Noah in most of the areas of the domain. CLM also exhibits positive differences compared to Noah, but smaller compared to NoahMP. Negative differences are obtained by RUC with six soil layers over the European part of the domain. RUC with nine soil layers has the smallest differences among all other schemes compared to the reference, which tend to be negative and correspond to lower values of ground heat flux by $2-5 \mathrm{~W} / \mathrm{m}^{2}$.

\subsection{Sub-domain variations}

A sub-regional analysis is performed using the annual time series derived from the six simulations with the different LSS for 2-m air and land surface temperature and precipitation and for each of the sub-domains shown in Fig. 2. Box and whiskers plots for the three variables mentioned above and for each of the twelve sub-domains are illustrated in Fig. 13, visually summarizing several statistical aspects (median, 75th and 25th percentiles, interquartile range, and maximum and minimum values) and 

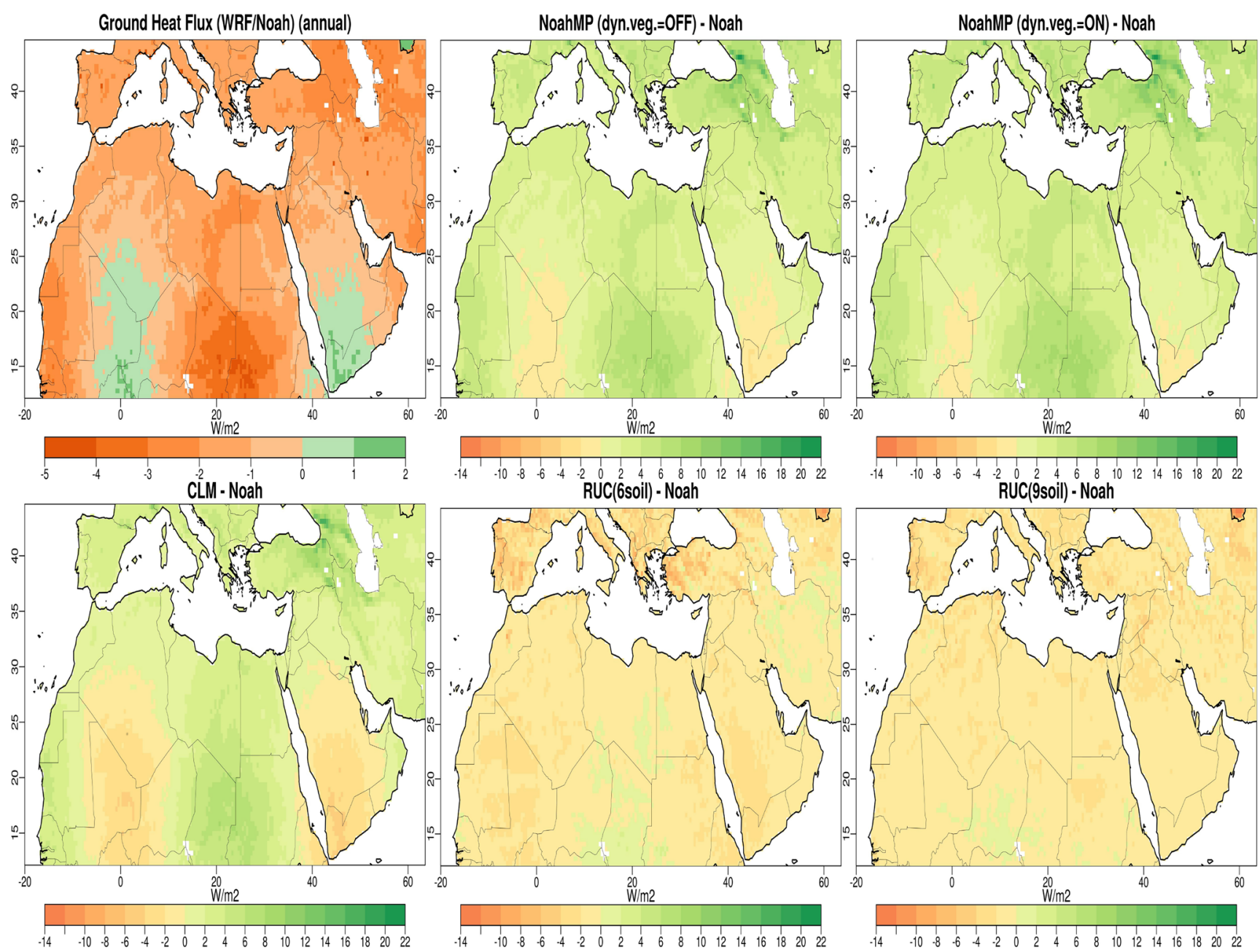

Fig. 12 Annual ground heat flux averaged for December 2000-November 2010 simulated by WRF with the Noah scheme (top left) and its difference from the runs with the NoahMP (dyn. veg.= off and on), CLM, RUC (6 and 9 soil layers) schemes

thus exposing the MENA areas where the LSS choice has a higher impact on the modelled climate.

The results for the sub-regions of MENA are displayed from west to east along the Mediterranean Sea towards southeastern Europe and the Middle East and then from east to west over northern Africa. The pattern of variation over the different sub-domains is the same for air and land temperature, being the reverse for precipitation, i.e., the warmest regions are also the driest (and vice versa).

The highest median values for the 2-m air and land surface temperatures are calculated for the Arabian peninsula (Tair $=25.7^{\circ} \mathrm{C}$ and Tland $=27.3{ }^{\circ} \mathrm{C}$ ) and the lowest for Anatolia (Tair $=9.7^{\circ} \mathrm{C}$ and Tland $=10.5^{\circ} \mathrm{C}$ ). The lowest precipitation (annual monthly average) is obtained for Egypt $(5 \mathrm{~mm})$ and the highest for the Balkans (125 $\mathrm{mm})$. The temperature and precipitation median values for the Arabian peninsula are comparable to the ones reported by global multi-model evaluation studies (Almazroui et al. 2017a; Almazroui et al. 2017b).
Information about the range of the three climatic parameters resulting from the use of the different land surface schemes can be inferred in Fig. 13 by the whiskers of each boxplot. Considering all sub-domains, the overall range in the air temperature $\left(\sim 0.7-2.4^{\circ} \mathrm{C}\right)$ is smaller than the range of the land surface temperature $\left(\sim 2-3.4{ }^{\circ} \mathrm{C}\right)$ among the different schemes. This is not a surprising finding since the LSS should primarily affect the surface and to a lesser extent the air above it. The variation in the precipitation lies within the interval of $5-25 \mathrm{~mm}$. The inter-quartile range (IQR) in the three variables associated with the $50 \%$ of the LSS-induced variation differs for the various sub-regions. The areas that have the smallest IQR for air, land temperature, and precipitation respectively are "Maghreb" $\left(0.12{ }^{\circ} \mathrm{C}\right)$, "Gulf" $\left(0.38{ }^{\circ} \mathrm{C}\right)$, and "central Mediterranean" (1.56 mm/month). The highest IQR values for the three variables are found for the "Arabian region" $\left(1.1{ }^{\circ} \mathrm{C}\right)$, "Libya" $\left(1.88{ }^{\circ} \mathrm{C}\right)$, and the "Balkans" (17.6 $\mathrm{mm} / \mathrm{month}$ ). 
(a) Annual Mean $2 \mathrm{~m}$ Air Temperature

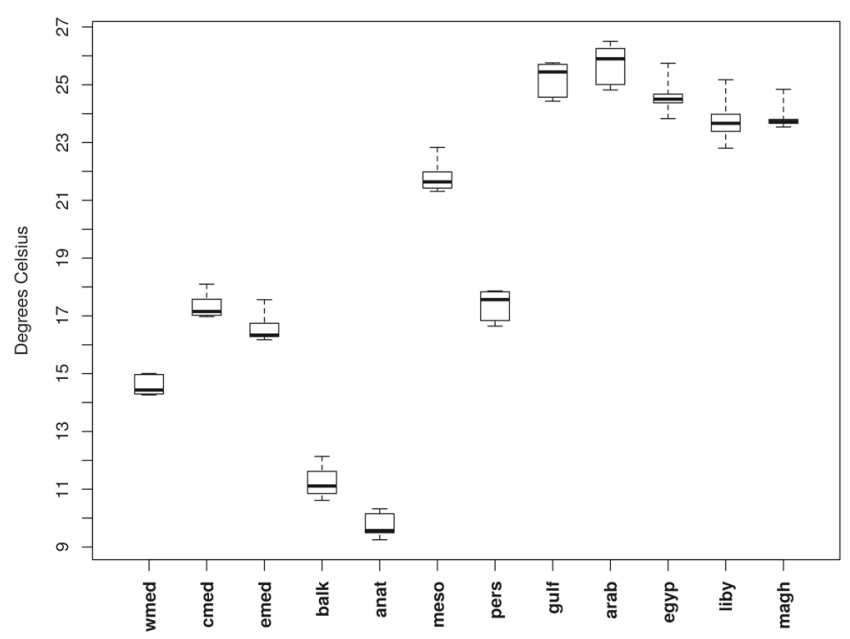

(b) Annual mean Land Surface Temperature

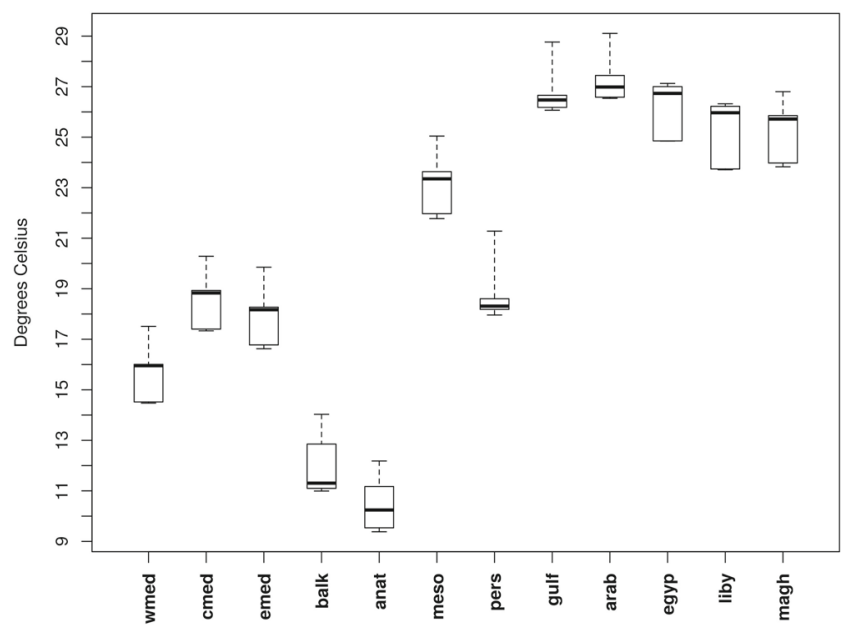

(c) Annual Total Precipitation

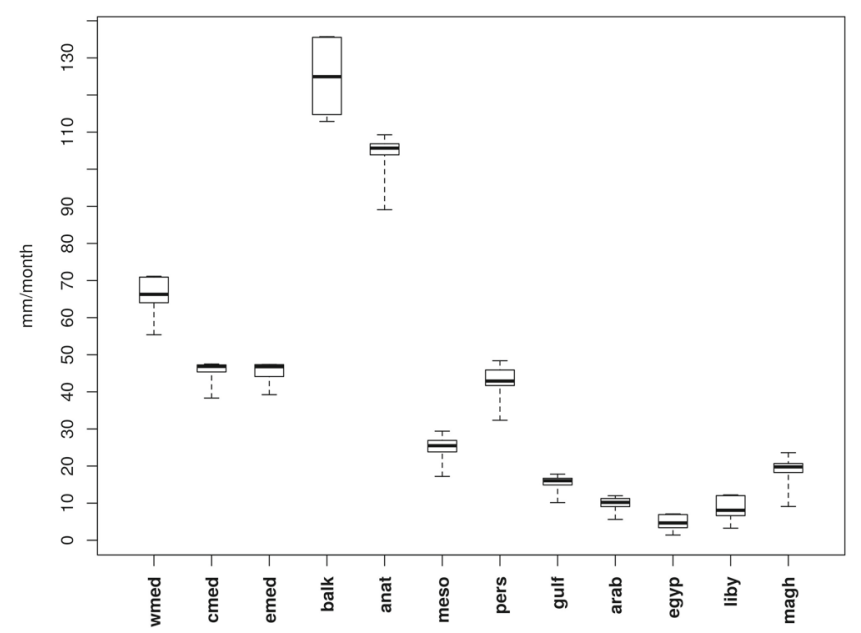

Fig. 13 Box and whiskers plots, derived from the six experiments of annual 10-year climatology a mean 2-m air and b land surface temperature and c total precipitation calculated for the 12 sub-regions (Anatolia, Balkans, western, central \& eastern Mediterranean, Mesopotamia, Persian region, Gulf, Arabian peninsula, Egypt,

The coefficient of variation facilitates the comparison of the LSS driven variations over the sub-domains (with different background values), and it is shown in Table 3 . Mean air temperature has a variation of $2-5 \%$ with the smallest calculated for the Maghreb region and the biggest for the Balkans and Anatolia. The three Mediterranean sub-domains exhibit low variation $(<3 \%)$, in accordance with (Bucchignani et al. 2016). Land surface temperature exhibits a spread of 3-10\% (lowest in the Middle East and highest in the Balkans and Anatolia). The more considerable variations over these northern parts of the MENA domain suggest a higher sensitivity to the LSS through the land surface coupling with the atmosphere, similar to the soil moisture-temperature feedback previously
Libya and Maghreb). The bold horizontal bar in the middle is the median value, the top and bottom boxes show the 75th and the 25th percentile respectively, the whole box represents the inter-quartile range (IQR) and the whiskers give the maximum and minimum values

found in the region (Zittis et al. 2014b). The coefficient of variation in precipitation is larger than that of the two temperature variables, with the lowest values obtained for the Mediterranean, Balkans, and Anatolia (7-9\%), higher for the Middle East (13-23\%) and the highest for North Africa (27-48\%).

\subsection{Surface energy balance}

In Fig. 14, the annual change of energy is derived from Eq. 1 (Section 2.4) and presented for each LSS used in the six experiments. Table 4 lists the deviation from an assumed energy balance for the different LSS options, averaged over the whole MENA domain, together with the absolute 
Table 3 The LSS-induced coefficient of variation of mean air temperature, land surface temperature and total precipitation calculated for the 12 sub-regions (Anatolia; Balkans; western, central, and eastern Mediterranean; Mesopotamia; Persian region; Arabian Gulf; Arabian peninsula; Egypt; Libya; and Maghreb)

\begin{tabular}{llll}
\hline \multicolumn{2}{l}{ Coefficient of Variation $=\sigma /$ mean } & & \\
\hline Sub-region & Tmean & Tland & Prcp \\
\hline wmed & 0.023 & 0.072 & 0.090 \\
cmed & 0.025 & 0.059 & 0.078 \\
emed & 0.031 & 0.066 & 0.071 \\
balk & 0.049 & 0.104 & 0.081 \\
anat & 0.043 & 0.102 & 0.070 \\
meso & 0.025 & 0.052 & 0.167 \\
pers & 0.030 & 0.066 & 0.130 \\
gulf & 0.024 & 0.037 & 0.176 \\
arab & 0.027 & 0.035 & 0.233 \\
egyp & 0.026 & 0.041 & 0.477 \\
liby & 0.034 & 0.049 & 0.418 \\
magh & 0.020 & 0.046 & 0.268 \\
\hline
\end{tabular}

values of the partitioning terms (net radiation and the three turbulent heat fluxes). The three simulations with the Noah schemes (top row of Fig. 14) seem to be the most "balanced"
Table 4 MENA domain averaged annual change of energy and its partitioning into net radiation and the three turbulent heat fluxes, for each LSS used.All in units of $\mathrm{W} / \mathrm{m}^{2}$

\begin{tabular}{llllll}
\hline LSS & $\frac{d H}{d t}$ & $R_{n}$ & LH & SH & G \\
\hline Noah & -0.7 & 84.71 & 13.85 & 72.90 & -1.34 \\
NoahMP (off) & -1.8 & 104.00 & 20.81 & 83.26 & 1.69 \\
NoahMP (on) & -1.7 & 104.03 & 20.87 & 82.60 & 2.28 \\
CLM & 3.0 & 101.52 & 24.61 & 73.66 & 0.24 \\
RUC (6 soil) & 2.7 & 109.17 & 26.86 & 82.42 & -2.77 \\
RUC (9 soil) & 2.6 & 109.52 & 27.32 & 82.28 & -2.71 \\
\hline
\end{tabular}

ones (with $\frac{d H}{d t}$ very slightly negative and whole domain average values of $-0.7,-1.8$, and $-1.7 \mathrm{~W} / \mathrm{m}^{2}$ respectively) in comparison with the rest of the LSSs. CLM shows a positive deviation from the assumed energy balance as the simulated net radiative flux is larger than the sum of the turbulent fluxes in the southern part of the domain, whereas the opposite is obtained for the latitudes above $35^{\circ} \mathrm{N}$ (with a MENA average of $+3.0 \mathrm{~W} / \mathrm{m}^{2}$ ). The RUC options deviate positively in most of the domains, apart from the southeastern areas (with a MENA average of +2.7 and +2.6 $\left.\mathrm{W} / \mathrm{m}^{2}\right)$.
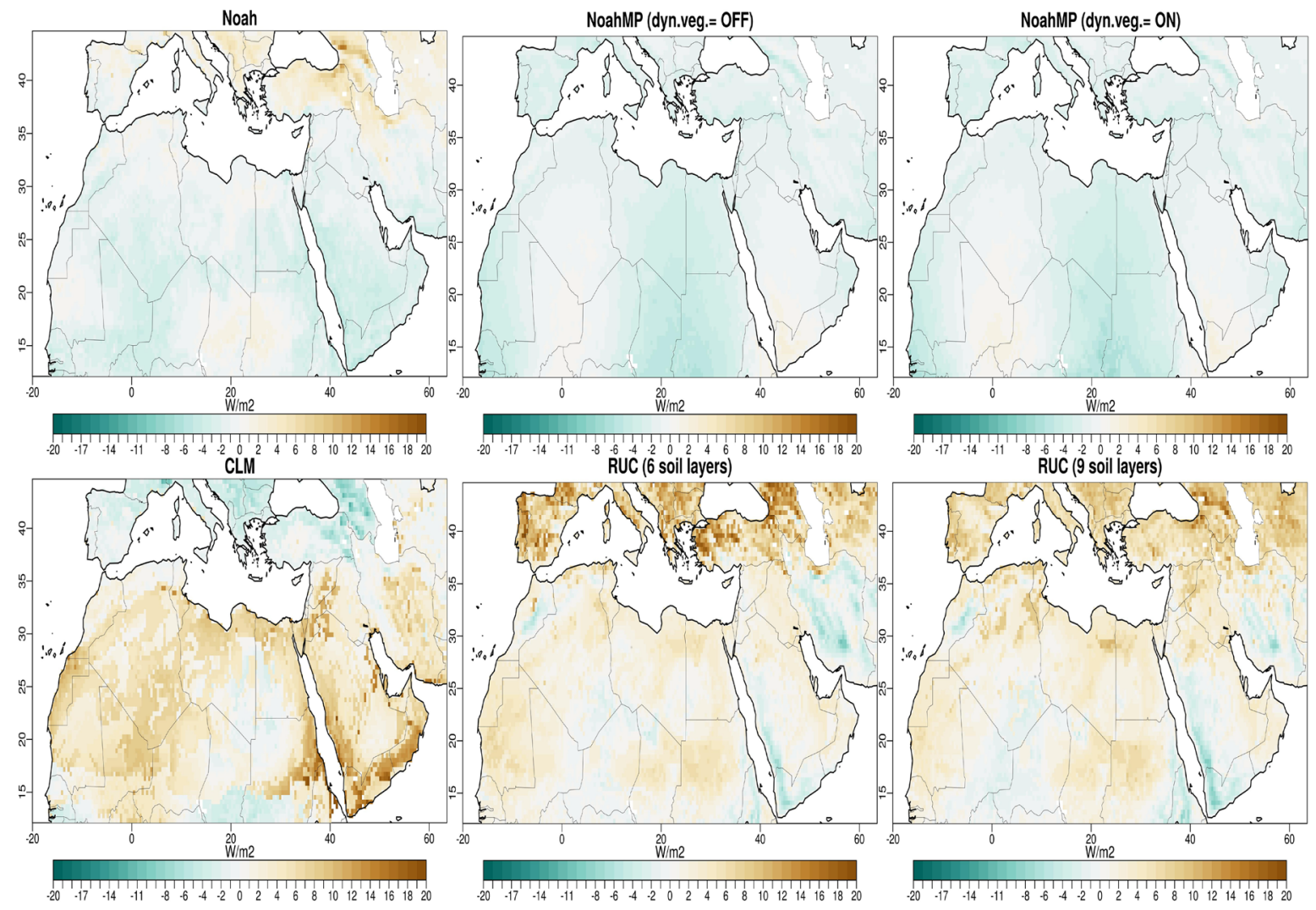

Fig. 14 Annual change of surface energy averaged for December 2000-11/2010 simulated by WRF with the following LSSs: Noah (top left), NoahMP dyn. veg.= OFF \& ON, CLM, RUC with 6 and 9 soil layers 
Table 5 The surface climate response (i.e., change $(\Delta)$ in air $\left(T_{a}\right)$ and land $\left(T_{l}\right)$ temperature, and precipitation $(\mathrm{Pr}))$ of the WRF model and the forcing $\Delta\left(\frac{d H}{d t}\right)$ of "perturbed" surface energy balance induced by the different LSSs with the model derived surface climate sensitivity for the MENA domain $(\lambda)$

\begin{tabular}{|c|c|c|c|c|c|c|c|}
\hline \multirow[t]{2}{*}{ LSS-ref } & \multicolumn{2}{|l|}{ Forcing } & \multicolumn{2}{|c|}{ Response } & \multicolumn{3}{|c|}{$\lambda=$ Response/forcing } \\
\hline & $\Delta\left(\frac{d H}{d t}\right)$ & $\Delta\left(T_{a}\right)$ & $\Delta\left(T_{l}\right)$ & $\Delta(P r)$ & $\lambda\left(T_{a}\right)$ & $\lambda\left(T_{l}\right)$ & $\lambda(P r)$ \\
\hline NoahMP(d.v=off)-Noah & -1.0 & -0.2 & -1.2 & 21.8 & 0.1 & 1.2 & -20.8 \\
\hline NoahMP(d.v=on)-Noah & -1.0 & -0.2 & -1.3 & 22.5 & 0.2 & 1.3 & -22.5 \\
\hline CLM-Noah & 3.7 & 0.9 & -1.3 & 16.7 & 0.2 & -0.4 & 4.5 \\
\hline RUC(6 soil)-Noah & 3.4 & -0.1 & -2.9 & 14.3 & 0.0 & -0.9 & 4.3 \\
\hline RUC(9 soil)-Noah & 3.4 & -0.3 & -3.0 & 14.6 & -0.1 & -0.9 & 4.4 \\
\hline Average all LSS & 1.7 & 0.0 & -2.0 & 18.0 & 0.1 & 0.1 & -6.0 \\
\hline
\end{tabular}

\subsection{LSS-induced model climate sensitivity}

The various terms for the calculation of the WRF LSSinduced climate sensitivity, using Eq. 2, are summarized in Table 5, based on the MENA domain averaged annual values. The forcing $\Delta\left(\frac{d H}{d t}\right)$ of the "perturbed" surface energy balance (induced by the different LSSs and derived from the data of Fig. 14) is slightly negative for the NoahMP runs, and for the simulations using CLM and RUC it takes higher positive values than the other runs. The response values for air and land temperature and precipitation are derived from the data of Figs. 3, 4, and 9, respectively. The derived climate sensitivity $\lambda$ is expressed in degrees Celsius per unit $\mathrm{W} / \mathrm{m}^{2}$ for air and land temperature and for the precipitation in units of $\mathrm{mm}$ per unit $\mathrm{W} / \mathrm{m}^{2}$.

The air temperature has negative sensitivity values for the simulations performed by RUC (both options) and positive with NoahMP (dyn. veg. = off and on) and the CLM, with an overall average of $0.1{ }^{\circ} \mathrm{C}$ per unit $\mathrm{W} / \mathrm{m}^{2}$. Regarding land surface temperature, the respective $\lambda$ values are higher than the ones for air temperature and with the same sign, apart from CLM where the sign reverses. The precipitationdiagnosed climate sensitivity is much higher (and negative) for the two Noah schemes $\left(\sim 20 \mathrm{~mm}\right.$ per $\left.\mathrm{W} / \mathrm{m}^{2}\right)$ and five times lower (and positive) for the other three schemes $(\sim$ $4 \mathrm{~mm}$ per $\mathrm{W} / \mathrm{m}^{2}$ ). If the above values are averaged over the five LSSs (however noting the opposite signs in our 5data point sample), overall climate sensitivity of this WRF model setup of about $+0.1{ }^{\circ} \mathrm{C}$ per $\mathrm{W} / \mathrm{m}^{2}$ for air and land temperature and $-6 \mathrm{~mm}$ per $\mathrm{W} / \mathrm{m}^{2}$ is derived.

\section{Summary and conclusions}

This work highlights the effect of land surface schemes on the modelled climate in the MENA region. The regional WRF climate model was coupled with four different land surface schemes in six simulations with a horizontal resolution of $50 \mathrm{~km}$ for the period 2000-2010, driven by ERA-Interim re-analyses. Computational constraints for the large MENA domain and multiple simulations precluded the study of higher resolution model versions. The simulation using Noah (default LSS in WRF) was considered the reference against which the other five simulations were compared in order to provide a measure of their effect.

A first, general inference is that aspects of the simulated climate using the NoahMP, CLM, and RUC land surface schemes significantly differ from the default Noah. The additional use of the available options for NoahMP (dynamic vegetation off and on) and RUC (6 and 9 layers) did not seem to have a discernible effect probably because vegetation does not play a critical role in the predominantly arid MENA region. The three schemes produce colder conditions overall, especially in the northern and southernmost parts of the domain. In the semi-arid and arid areas between $15-30^{\circ} \mathrm{N}$ the three schemes overestimate temperature (air and land), compared to the default Noah. This pattern is mirrored in the respective differences in SW upward radiation and LW upwelling radiation and to a certain degree in the sensible heat flux, and it is stronger and more consistent for the NoahMP and CLM, rather than RUC. The three LSSs are all very similar in simulating slightly higher rainfall $(10-20 \mathrm{~mm})$ than Noah throughout the MENA domain, and much higher $(>100 \mathrm{~mm})$ in parts of the Sahel. This is matched closely in space by their latent heat flux differences showing an overestimation compared to Noah, overall by $10-20 \mathrm{~W} / \mathrm{m}^{2}$ and $100 \mathrm{~W} / \mathrm{m}^{2}$ in the Sahel.

The spread of the annual climatologies of the three main surface climatic parameters from the different LSS simulations was derived for 12 MENA sub-domains, thus providing a spatially representative measure of their effect, compared to the reference Noah. For air temperature, this was in the range of $0.7-2.4^{\circ} \mathrm{C}$ and for land surface temperature $2-3.4^{\circ} \mathrm{C}$, and it was consistent for the warmer (Middle East, North Africa) and the cooler (Balkans, Anatolia) parts of the domain. The variation of the total precipitation was $5-25 \mathrm{~mm}$. These differences are comparable to those obtained in other RCM physics sensitivity studies with altered datasets of land cover properties (Bucchignani et al. 2016; De Meij et al. 2018), pointing also to the role of the driving land surface data (not considered in our experiments). 
The calculation of the WRF surface energy balance revealed that the default Noah is the most "balanced" scheme with $\mathrm{dH} / \mathrm{dt} \simeq-1 \mathrm{~W} / \mathrm{m}^{2}$ and NoahMP $\simeq-2$ $\mathrm{W} / \mathrm{m}^{2}$ (MENA domain averages). CLM and RUC show a positive deviation from the assumed energy balance of $\simeq+3 \mathrm{~W} / \mathrm{m}^{2}$. Thus, the two "non-native" LSSs alter the sign and cause the largest deviations in the energy balance. The difference in the surface energy balance from the various LSSs against the one from the reference Noah can be applied as forcing for the model climate that induces a surface climate response. Hence, an LSS-induced climate sensitivity was determined for the air temperature, which is small overall $\left(0.1^{\circ} \mathrm{C}\right.$ per $\left.\mathrm{W} / \mathrm{m}^{2}\right)$.

In conclusion, the use of other than the most commonly used LSS (Noah) in these MENA-CORDEX domain WRF simulations resulted in non-negligible differences in key surface climate variables, such as 1-2 degrees Celsius in air temperature, which are comparable to the magnitude of the anthropogenic warming signal projected for the coming decades in the region (Lelieveld et al. 2016). This affects the estimates of the expected climate change-related impacts, which has been shown in a separate study based on the same model output (Constantinidou et al. 2019). It is, therefore, important to carefully select the most suitable land surface scheme for any particular model and geographical domain. For the WRF application over the MENA region, a forthcoming study will evaluate against observations the different LSSs and recommend the most suitable one.

Acknowledgements We thank two anonymous reviewers for their constructive comments.

Funding information Part of this work was co-funded by the European Regional Development Fund and the Republic of Cyprus through the Research Innovation Foundation CELSIUS Project EXCELLENCE/1216/0039.

Open Access This article is licensed under a Creative Commons Attribution 4.0 International License, which permits use, sharing, adaptation, distribution and reproduction in any medium or format, as long as you give appropriate credit to the original author(s) and the source, provide a link to the Creative Commons licence, and indicate if changes were made. The images or other third party material in this article are included in the article's Creative Commons licence, unless indicated otherwise in a credit line to the material. If material is not included in the article's Creative Commons licence and your intended use is not permitted by statutory regulation or exceeds the permitted use, you will need to obtain permission directly from the copyright holder. To view a copy of this licence, visit http://creativecommons. org/licenses/by/4.0/.

\section{References}

Almazroui M (2016a) Regcm4 in climate simulation over cordexmena/arab domain: selection of suitable domain, convection and land-surface schemes. Int J Climatol 36(1):236-251. https://doi.org/10.1002/joc. 4340

Almazroui M, Islam MN, Al-Khalaf AK, Saeed F (2016b) Best convective parameterization scheme within regCM4 to downscale CMIP5 multi-model data for the CORDEXMENA/arab domain. Theor Appl Climatol 124(3-4):807-823. https://doi.org/10.1007/s00704-015-1463-5

Almazroui M, Nazrul Islam M, Saeed S, Alkhalaf AK, Dambul R (2017a) Assessment of uncertainties in projected temperature and precipitation over the arabian peninsula using three categories of CMIP5 multimodel ensembles. Earth Systems and Environment 1(2):1-20. https://doi.org/10.1007/s41748-017-0027-5

Almazroui M, Saeed S, Islam MN, Khalid MS, Alkhalaf AK, Dambul $\mathrm{R}$ (2017b) Assessment of uncertainties in projected temperature and precipitation over the Arabian Peninsula: a comparison between different categories of CMIP3 models. Earth Systems and Environment 1(2):1-21. https://doi.org/10.1007/s41748-0170012-Z

Benjamin S, Bleck R, Brown J, Brundage K, Devenyi D, Grell G, Kim D, Manikin G, Schlatter T, Schwartz B, Smirnova T, Weygandt S, Alamos L (2004) Mesoscale weather prediction with the RUC Hybrid Isentropic-Sigma Coordinate Model and Data Assimilation System Operational Numerical Weather Prediction., the Symposium on the 50th Anniversary of Operational Numerical Weather Prediction pp 495-518

Betts AK (2009) Land-surface-atmosphere coupling in observations and mModels. Journal of Advances in Modeling Earth Systems, 1(3) https://doi.org/10.3894/JAMES.2009.1.4

Bucchignani E, Cattaneo L, Panitz HJ, Mercogliano P (2016) Sensitivity analysis with the regional climate model COSMOCLM over the CORDEX-MENA domain. Meteorog Atmos Phys 128(1):73-95. https://doi.org/10.1007/s00703-015-0403-3

Cheng S, Huang J, Ji F, Lin L (2017) Uncertainties of soil moisture in historical simulations and future projections. Journal of Geophysical Research 122(4):2239-2253. https://doi.org/10.1002/ 2016JD0258712016JD025871

Chotamonsak C, Salathė EP, Kreasuwan J, Chantara S, Siriwitayakorn K (2011) Projected climate change over Southeast Asia simulated using a WRF regional climate model. Atmos Sci Lett 12(2):213219. https://doi.org/10.1002/asl.313

Constantinidou K, Hadjinicolaou P, Zittis G, Lelieveld J (2016) Effects of climate change on the yield of winter wheat in the eastern Mediterranean and Middle East. Clim Res 69(2):129-141. https://doi.org/10.3354/cr01395

Constantinidou K, Zittis G, Hadjinicolaou P (2019) Variations in the simulation of climate change impact indices due to different land surface schemes over the Mediterranean, Middle East and Northern Africa. Atmosphere 10(1):26. https://doi.org/10.3390/ atmos 10010026

Crawley MJ (2015) Statistics : an introduction using R, 2nd Edition, John Wiley \& Sons

Davin EL, Maisonnave E, Seneviratne SI (2016) Is land surface processes representation a possible weak link in current Regional Climate Models? Environmental Research Letters 11(7):1-8. https://doi.org/10.1088/1748-9326/11/7/074027

De Meij A, Zittis G, Christoudias T (2018) On the uncertainties introduced by land cover data in high-resolution regional simulations. Meteorology and Atmospheric Physics 131(5):12131223. https://doi.org/10.1007/s00703-018-0632-3

Dee DP, Uppala SM, Simmons AJ, Berrisford P, Poli P, Kobayashi S, Andrae U, Balmaseda MA, Balsamo G, Bauer P, Bechtold P, Beljaars AC, van de Berg L, Bidlot J, Bormann N, Delsol C, Dragani R, Fuentes M, Geer AJ, Haimberger L, Healy SB, Hersbach H, Hólm EV, Isaksen L, Kållberg P, Köhler M, Matricardi M, Mcnally AP, Monge-Sanz BM, Morcrette 
JJ, Park BK, Peubey C, de Rosnay P, Tavolato C, Thépaut JN, Vitart F (2011) The ERA-Interim reanalysis: configuration and performance of the data assimilation system. Quarterly Journal of the Royal Meteorological Society 137(656):553-597. https://doi.org/10.1002/qj.828

Fita L, Polcher J, Giannaros TM, Lorenz T, Milovac J, Sofiadis G, Katragkou E, Bastin S (2019) CORDEX-WRF V1.3: Development of a module for the Weather Research and Forecasting (WRF) model to support the CORDEX community. Geosci Model Dev 12(3):1029-1066. https://doi.org/10.5194/gmd-12-10292019

Giorgi F, Gutowski WJ (2015) Regional dynamical downscaling and the CORDEX initiative. Annual Review of Environment and Resources 40(1):467-490. https://doi.org/10.1146/annurevenviron-102014-021217

Giorgi F, Jones C, Asrar G (2009) Addressing climate information needs at the regional level: the CORDEX framework. World Meteorological Organization (WMO) Bulletin 58(3):175

Hartmann DL (2016) Chapter 10 - Climate sensitivity and feedback mechanisms. In: Hartmann DL (ed) Global Physical Climatology (Second Edition), second edi edn, Elsevier, Boston, pp 293-323, https://doi.org/1016/B978-0-12-328531-7.00010-4

Katragkou E, Garciá-Diéz M, Vautard R, Sobolowski S, Zanis P, Alexandri G, Cardoso RM, Colette A, Fernandez J, Gobiet A, Goergen K, Karacostas T, Knist S, Mayer S, Soares PM, Pytharoulis I, Tegoulias I, Tsikerdekis A, Jacob D (2015) Regional climate hindcast simulations within EURO-CORDEX: evaluation of a WRF multi-physics ensemble. Geoscientific Model Development 8(3):603-618. https://doi.org/10.5194/gmd-8-603-2015

Kim D, Kang S, Choi M (2016) Land surface models evaluation for two different land-cover types: cropland and forest. Terrestrial, Atmospheric and Oceanic Sciences 27(1):153-167. https://doi.org/10.3319/TAO.2015.09.14.02(Hy)

Knist S, Goergen K, Buonomo E, Christensen OB, Colette A, Cardoso RM, Fealy R, Fernández J, García-Díez M, Jacob D, Kartsios S, Katragkou E, Keuler K, Mayer S, van Meijgaard E, Nikulin G, Soares PMM, Sobolowski S, Szepszo G, Teichmann C, Vautard R, Warrach-Sagi K, Wulfmeyer V, Simmer C (2017) Land-atmosphere coupling in euro-cordex evaluation experiments. Journal of Geophysical Research: Atmospheres 122(1):79-103. https://doi.org/10.1002/2016JD025476

Lawrence DM, Oleson KW, Flanner MG, Thornton PE, Swenson SC, Lawrence PJ, Zeng X, Yang ZL, Levis S, Sakaguchi K, Bonan GB, Slater AG (2011) Parameterization improvements and functional and structural advances in Version 4 of the Community Land Model. Journal of Advances in Modeling Earth Systems 3(3):1-27. https://doi.org/10.1029/2011MS000045

Lelieveld J, Hadjinicolaou P, Kostopoulou E, Chenoweth J, El Maayar M, Giannakopoulos C, Hannides C, Lange MA, Tanarhte M, Tyrlis E, Xoplaki E (2012) Climate change and impacts in the Eastern Mediterranean and the Middle East. Climatic Change 114(3-4):667-687. https://doi.org/10.1007/s10584-012-0418-4

Lelieveld J, Proestos Y, Hadjinicolaou P, Tanarhte M, Tyrlis E, Zittis G (2016) Strongly increasing heat extremes in the Middle East and North Africa (MENA) in the 21st century. Climatic Change 137(1-2):245-260. https://doi.org/10.1007/s10584-016-1665-6

Lin Y, Dong W, Zhang M, Xie Y, Xue W, Huang J, Luo Y (2017) Causes of model dry and warm bias over central U.S. and impact on climate projections. Nature Communications 8(1):1-8. https://doi.org/10.1038/s41467-017-01040-2

Mitchell K, Ek M, Wong V, Lohmann D, Koren V, Schaake J, Duan Q, Gayno G, Moore B, Grunmann P, Tarpley D, Ramsay B, Chen F, Kim J, Hl Pan, Lin Y, Marshall C, Mahrt L, Meyers T, Ruscher P (2005) Noah land surface model (LSM) user's guide. NCAR Research Application Laboratory (RAL), pp 1-26
Nikulin G, Jones C, Giorgi F, Asrar G, Büchner M, Cerezo-Mota R, Christensen OB, Déqué M, Fernandez J, Hänsler A, van Meijgaard E, Samuelsson P, Sylla MB, Sushama L (2012) Precipitation climatology in an ensemble of CORDEX-Africa regional climate simulations. Journal of Climate 25(18):60576078. https://doi.org/10.1175/JCLI-D-11-00375.1

Niu GY, Yang ZL, Mitchell KE, Chen F, Ek MB, Barlage M, Kumar A, Manning $\mathrm{K}$, Niyogi D, Rosero $\mathrm{E}$, Tewari M, Xia Y (2011) The community Noah land surface model with multiparameterization options (Noah-MP): 1. Model description and evaluation with local-scale measurements. Journal of Geophysical Research Atmospheres 116(12):1-19. https://doi.org/10.1029/2010JD015139

Oleson KW, Lawrence DM, Bonan GB, Flanner MG, Kluzek E, Lawrence PJ, Levis S, Swenson SC, Thornton PE (2010) Technical description of version 4.0 of the Community Land Model (CLM). NCAR/TN-478 + STR. Boulder, C(April):National Center for Atmospheric Research, papers2://publication/uuid/ 6858EE7A-C77E-4439-832D-CEC2791FBE BA

Pielke RA (2001) Influence of the spatail distribution of vegetation and soils on the predictions of cumulus convective rainfall.. Reviews of Geophysics 39(2):151-177. https://doi.org/10.1029/1999RG000072

Pitman AJ (2003) The evolution of, and revolution in, land surface schemes designed for climate models. Int J Climatol 23(5):479510. 10.1002/joc. 893

Salathe EP, Leung LR, Qian Y, Zhang Y (2010) Regional climate model projections for the State of Washington. Clim Chang 102(12):51-75. 10.1007/s10584-010-9849-y

Sellers PJ, Dickinson RE, Randall DA, Betts AK, Hall FG, Berry JA, Collatz GJ, Denning AS, Mooney HA, Nobre CA, Sato N, Field CB, Henderson-Sellers A (1997) Modeling the exchanges of energy, water, and carbon between continents and the atmosphere. SCIENCE 275(5299):502-509. https://doi.org/10.1126/science.275.5299.502

Seneviratne SI, Stoeckli R (2008) The role of land-atmosphere interactions for climate variability in Europe. In: Bronnimann S, Luterbacher J, Ewen T, Diaz HF, Stolarski RS, Neu $\mathrm{U}$ (eds) Climate variability and extremes during the past 100 years, Swiss RE NCCR Climate; Swiss Natl Sci Fdn; ProClim; Univ Bern, Max \& Elsa Beer Brawand Fdn, Springer, PO BOX 17, 3300 AA DORDRECHT, NETHERLANDS, Advances in Global Change Research, vol 33, pp 179-193, https://doi.org/10.1007/978-1-4020-6766-2_12

Seneviratne SI, Corti T, Davin EL, Hirschi M, Jaeger EB, Lehner I, Orlowsky B, Teuling AJ (2010) Earth-Science Reviews Investigating soil moisture - climate interactions in a changing climate : a review. Earth Science Reviews 99(3-4):125-161. https://doi.org/10.1016/j.earscirev.2010.02.004

Sippel S, Zscheischler J, Mahecha MD, Orth R, Reichstein M, Vogel M, Seneviratne SI (2017) Refining multi-model projections of temperature extremes by evaluation against land-atmosphere coupling diagnostics. Earth System Dynamics 8(2):387-403. https://doi.org/10.5194/esd-8-387-2017

Soares PM, Cardoso RM, Miranda PM, de Medeiros J, Belo-Pereira M, Espirito-Santo F (2012) WRF high resolution dynamical downscaling of ERA-interim for Portugal. Clim Dyn 39(910):2497-2522. https://doi.org/10.1007/s00382-012-1315-2

Soares PMM, Careto JAM, Cardoso RM, Goergen K, Trigo RM (2019) Land-atmosphere coupling regimes in a future climate in africa: From model evaluation to projections based on cordex-africa. Journal of Geophysical Research: Atmospheres 124(21):11118 11142. https://doi.org/10.1029/2018JD029473

von Storch H, Zwiers FW (1999) Statistical analysis in Climate Research. Cambridge University Press, Cambridge 
Warrach-Sagi K, Schwitalla T, Wulfmeyer V, Bauer HS (2013) Evaluation of a climate simulation in Europe based on the WRF-NOAH model system: Precipitation in Germany. Clim Dyn 41(3-4):755-774. https://doi.org/10.1007/s00382-013-1727-7

Zachariadis T, Hadjinicolaou P (2014) The effect of climate change on electricity needs - a case study from Mediterranean Europe. Energy 76:899-910. https://doi.org/10.1016/j.energy.2014.09. 001

Zittis G, Hadjinicolaou P (2017) The effect of radiation parameterization schemes on surface temperature in regional climate simulations over the MENA-CORDEX domain. Int J Climatol 37(10):3847-3862. 10.1002/joc.4959

Zittis G, Hadjinicolaou P, Lelieveld J (2014a) Comparison of WRF model physics parameterizations over the MENA-CORDEX domain. American Journal of Climate Change 03(05):490-511. https://doi.org/10.4236/ajcc.2014.35042
Zittis G, Hadjinicolaou P, Lelieveld J (2014b) Role of soil moisture in the amplification of climate warming in the eastern Mediterranean and the Middle East. Climate Research 59(1):2737. https://doi.org/10.3354/cr01205

Zittis G, Hadjinicolaou P, Fnais M, Lelieveld J (2016) Projected changes in heat wave characteristics in the eastern Mediterranean and the Middle East. Regional Environmental Change 16(7):1863-1876. https://doi.org/10.1007/s10113-014-0753-2

Zittis G, Hadjinicolaou P, Klangidou M, Proestos Y, Lelieveld J (2019) A multi-model, multi-scenario, and multi-domain analysis of regional climate projections for the Mediterranean. Reg Environ Chang 19(8):2621-2635. https://doi.org/10.1007/s10113-01901565-w

Publisher's note Springer Nature remains neutral with regard to jurisdictional claims in published maps and institutional affiliations. 